\title{
Cartilage Repair Using Hydrogels: A Critical Review of in Vivo Experimental Designs
}

\author{
${ }_{3}$ C. A. Vilela, ${ }^{\dagger, \downarrow, \S, \|}$ C. Correia, ${ }^{\#}$ J. M. Oliveira, ${ }^{\dagger, \ddagger}$ R. A. Sousa, ${ }^{\#}$ J. Espregueira-Mendes, ${ }^{\dagger, \ddagger, \S, \perp}$ \\ 4 and R. L. Reis*, ${ }^{\dagger}$, क, \\ $5{ }^{\dagger} 3 B^{\prime}$ s Research Group, University of Minho, Guimarães, Portugal \\ 6 'ICVS/3B's-PT Government Associate Laboratory, Braga/Guimarães, Portugal \\ $7{ }^{8}$ Life and Health Sciences Research Institute (ICVS), University of Minho, Braga, Portugal \\ 8 "Orthopaedic Department, Centro Hospitalar do Alto Ave, Guimarães, Portugal \\ $9^{\perp}$ Clínica do Dragão, Espregueira-Mendes Sports Centre, Porto, Portugal \\ $10{ }^{\#}$ Stemmatters, Biotecnologia e Medicina Regenerativa SA, Guimarães, Portugal
}

11 ABSTRACT: This review analyzes the outcomes and 12 technical aspects of in vivo studies published in the past 13 decade using gels and hydrogels for cartilage repair. Using 14 PubMed search engine, original research publications during 15 the period of $2002 / 01 / 01$ to $2015 / 04 / 30$ identified 115 16 published papers. Of these, 3 studies failed to find a statistically 17 significant improvement of treatment group as compared to 18 control and 18 studies did not clearly identify hyaline-like 19 cartilage formation in the treated groups. The most frequent 20 repaired lesion was the rabbit acute full thickness trochlear 21 defect, using a scaffold combining a gel or hydrogel and other 22 material. One third of the scaffolds were cell-free (35\%) and 23 the majority of the studies did not use growth factors (71\%).

24 The present review may constitute a useful tool in design of future studies, as limitations of study designs are pointed and results 25 in terms of translation to human application is discussed.

26 KEYWORDS: cartilage repair, hydrogels, gels, in vivo, animal, tissue engineering

\section{INTRODUCTION}

27 Articular cartilage has limited intrinsic capacity for self-repair, 28 because of the lack of vascular, neural, and lymphatic networks, 29 as well as absence of progenitor cells. ${ }^{1,2}$ According to Hjelle et 30 al, cartilage lesions were found in $60 \%$ of patients submitted to 31 knee arthroscopy. ${ }^{3}$ Cartilage lesions commonly progress to 32 osteoarthritis (OA), as a final state of disease evolution. ${ }^{2,4}$ 33 Presently, it is estimated that $10-15 \%$ of adults over 60 years 34 old show some symptoms of disease and by 2050, 130 million 35 people will suffer from osteoarthritis worldwide. ${ }^{5}$ The clinical 36 and economic impact is impressive, as the estimated direct and 37 indirect costs related to OA has surpassed $\$ 65$ billion annually. ${ }^{6}$

38 At earlier stages of cartilage damage, current therapies for 39 cartilage repair of lesions are not satisfactory as they fail to 40 restore a normal hyaline cartilage. ${ }^{7-9}$ Surgical approaches can 41 include microfracture, resurfacing techniques, and osteochon42 dral grafting. ${ }^{8-10}$ Autologous chondrocyte implantation (ACI) 43 and matrix-assisted autologous chondrocyte implantation 44 (MACI) are advanced approaches for regeneration of cartilage 45 lesions. ${ }^{9,10}$

46 Microfracture and resurfacing techniques are easy to perform, 47 cost competitive, widely adopted, and well-documented 48 techniques that relieve symptomatic patients. However, regenerated tissue is composed mostly by fibrocartilage, thus 49 providing short-term positive results in small cartilage 50 lesions. ${ }^{8,10}$

Osteochondral grafting, the direct transplantation of an 52 osteochondral autograft (mosaicplasty) or allograft, is the only 53 technique available that satisfactorily restores hyaline cartilage. ${ }^{4} 54$ However, donor site morbidity, risk of disease transmission, 55 possible graft-versus-host immune response (in the case of 56 allografts) and osteoarthritic exacerbation can occur due to lack 57 of congruency between treated and untreated surfaces, thus 58 limiting the use of those techniques. ${ }^{4}$

On the other hand, ACI and MACI are expensive techniques, 60 which demand complex protocols and two different surgeries. 61 Promising results have been reported, ${ }^{4}$ but poor consistence of 62 clinical outcomes with time, cells and/or cartilage fragment 63 loosening, arthrofibrosis, osteophytes development, synovitis, 64 infection and chondromalacea have been described. ${ }^{4,10} \quad 65$

Many of the limitations of current available treatments justify 66 the quest for more effective approaches and development of 67

Received: June 6, 2015

Accepted: August 13, 2015 


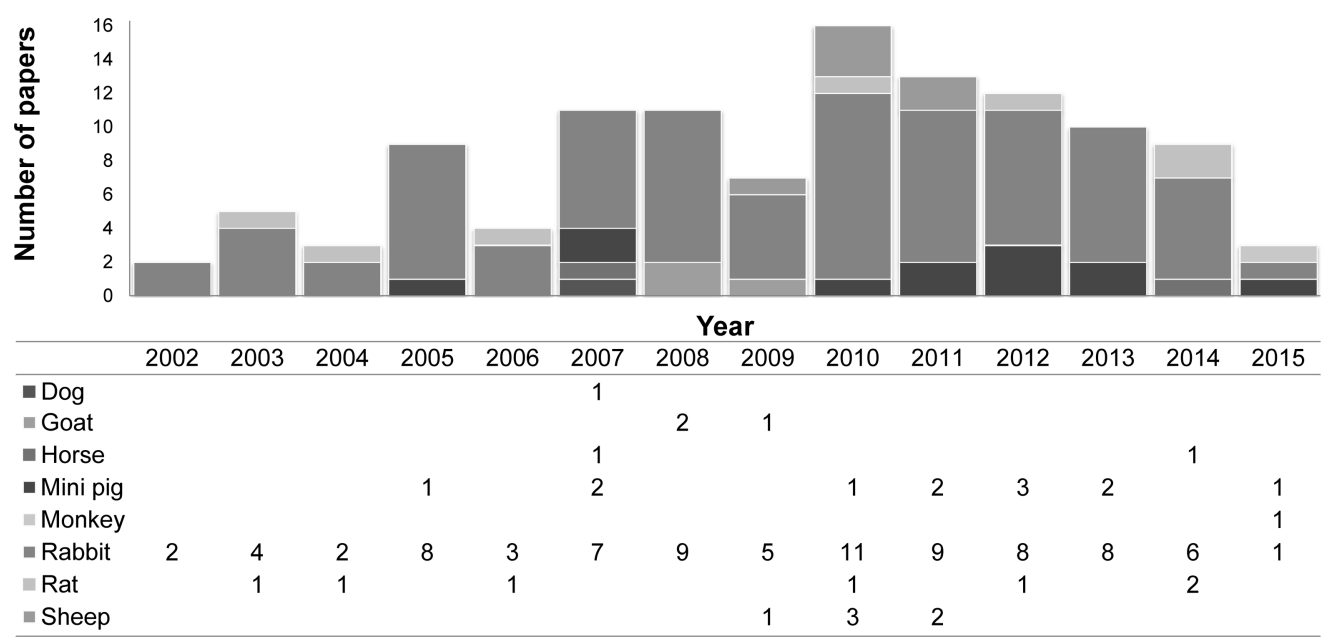

Figure 1. Number of original scientific publications per year published between 2002 and 2014 reporting in vivo experiments on cartilage repair according to animal model.

68 new biomaterials for cartilage repair. Interestingly, hydrogels 69 have attracted great deal of attention because of its performance 70 characteristics, i.e., are soft, of synthetic or natural origin, and $71 \mathrm{can}$ form three-dimensional networks that can be tuned for its 72 biocompatibility, bioadhesiveness, and biodegradability. ${ }^{11,12}$ 73 Hydrogels present other advantageous features for tissue 74 engineering applications, ${ }^{11-14}$ such as extracellular matrix 75 mimetic; swelling ability while maintaining shape; capability 76 to undergo volume phase or sol-gel phase transitions in 77 response to physical and/or chemical stimuli; tunable surface 78 and bulk properties to modulate cells adhesion and 79 thrombogenicity; support to high diffusion kinetics of nutrients 80 and metabolic products within the construct.

81 There are several chemical or physical cross-linking 82 techniques, photopolymerization, or even microfabrication 83 technologies, ${ }^{13,15,16}$ which can optimize hydrogel physicochem84 ical characteristics and biological behavior, ${ }^{13}$ and improve 85 performance of hydrogels in cartilage tissue engineering 86 strategies. Furthermore, hydrogels can be combined with 87 other materials improving its properties. ${ }^{17-19}$

88 The application of hydrogels as volume fillers and cell 89 carriers can contribute significantly to the development of more 90 effective regeneration strategies ${ }^{20}$ in irregular shape cartilage 91 defects. Additionally, the opportunity to treat such lesions by a 92 single step procedure using simpler surgical protocols, in which 93 an injectable solution is delivered by a minimally invasive 94 procedure, can minimize significantly treatment cost, improve 95 patient safety and comfort, and support treatment in an 96 outpatient setting.

97 This review compiles in vivo studies reporting the use of 98 hydrogels for repairing cartilage lesions and analyzes its 99 performance in different animal models. A thorough analysis 100 of experimental variables was further performed, constituting a 101 useful tool for researchers when designing future in vivo studies 102 for cartilage repair.

\section{METHODS}

103 2.1. Keyword-Based Search. Original research publications were 104 identified by the use of PubMed search engine, during the period 105 comprised between 2002/01/01 and 2015/04/30, and using the 106 following keywords: "cartilage", "osteochondral", "cartilage repair", 107 "tissue engineering", "scaffold", "cells", "gel”, "gels", "hydrogel", and 108 "hydrogels", using AND/OR Boolean operators. The terms such as “eye”, "heart”, “tooth”, "skin”, “root”, “dermal”, “dentin”, “cardiovas- 109 cular", "hepatic", "gastric", "gastrointestinal", and "biochemistry" were 110 excluded.

2.2. Inclusion/Exclusion Selection. All abstracts were evaluated 112 by four independent reviewers based on the following inclusion 113 criteria: English language, and experimental protocol reporting in vivo 114 use of hydrogels in repair of cartilage defects. The following exclusion 115 were applied: Other language rather than English; in vitro studies; 116 studies not involving use of hydrogels; studies reporting use of 117 hydrogels in other application contexts or studies in which the 118 hydrogel could not be considered as a scaffold. Whenever the abstract 119 was unclear or insufficient for determination of its inclusion/exclusion, 120 the Materials and Methods section and/or the complete publication 121 were analyzed before a decision was made.

2.3. Evaluation and Final Selection. After selection of abstracts, 123 a second evaluation was carried out, during which all publications were 124 analyzed and discussed among the four reviewers in order to produce 125 the final list of publications to be overviewed.

2.4. Full Text Review. All included articles were submitted to a 127 full-text review. For each paper, the respective list of references was 128 verified to identify possible relevant studies that might have been 129 undetected through PubMed-based search.

130

\section{RESULTS}

3.1. Publication Selection and Review. Keyword based 131 search identified a total of 14295 publications. After inclusion/ 132 exclusion selection, 902 papers related to study of articular 133 cartilage repair have been identified. Then, evaluation and final 134 selection of those papers, according to defined inclusion and 135 exclusion criteria, identified a total of 93 papers. During the 136 selection process, 809 studies have been excluded due to several 137 reasons, such as in vitro experimental protocol, experiments not 138 aimed at repairing cartilage defects, or papers reporting clinical 139 investigations. For each paper, the list of references was verified, 140 which allowed identification of 22 additional publications. 141 Herein, the total number of published original articles 142 identified, reviewed and included was 115 .

3.2. Distribution of Publications Per Year. The distribution of publications per year is shown in Figure 1. $145 \mathrm{fl}$ Between 2002 and 2010, the number of publications reporting 146 in vivo experiments concerning cartilage repair have increased 147 every year. After 2010, the number of publications per year 148 appears to have stabilized between 10 and 13 papers per year. 149

3.3. Animal Models. Upon analysis of the publications, 150 several outcomes were obtained regarding animal models and $151 \mathrm{f} 2$ 
152 respective experimental protocol (Figure 2). According to 153 Figure 2A, the rabbit model was the most common for studying
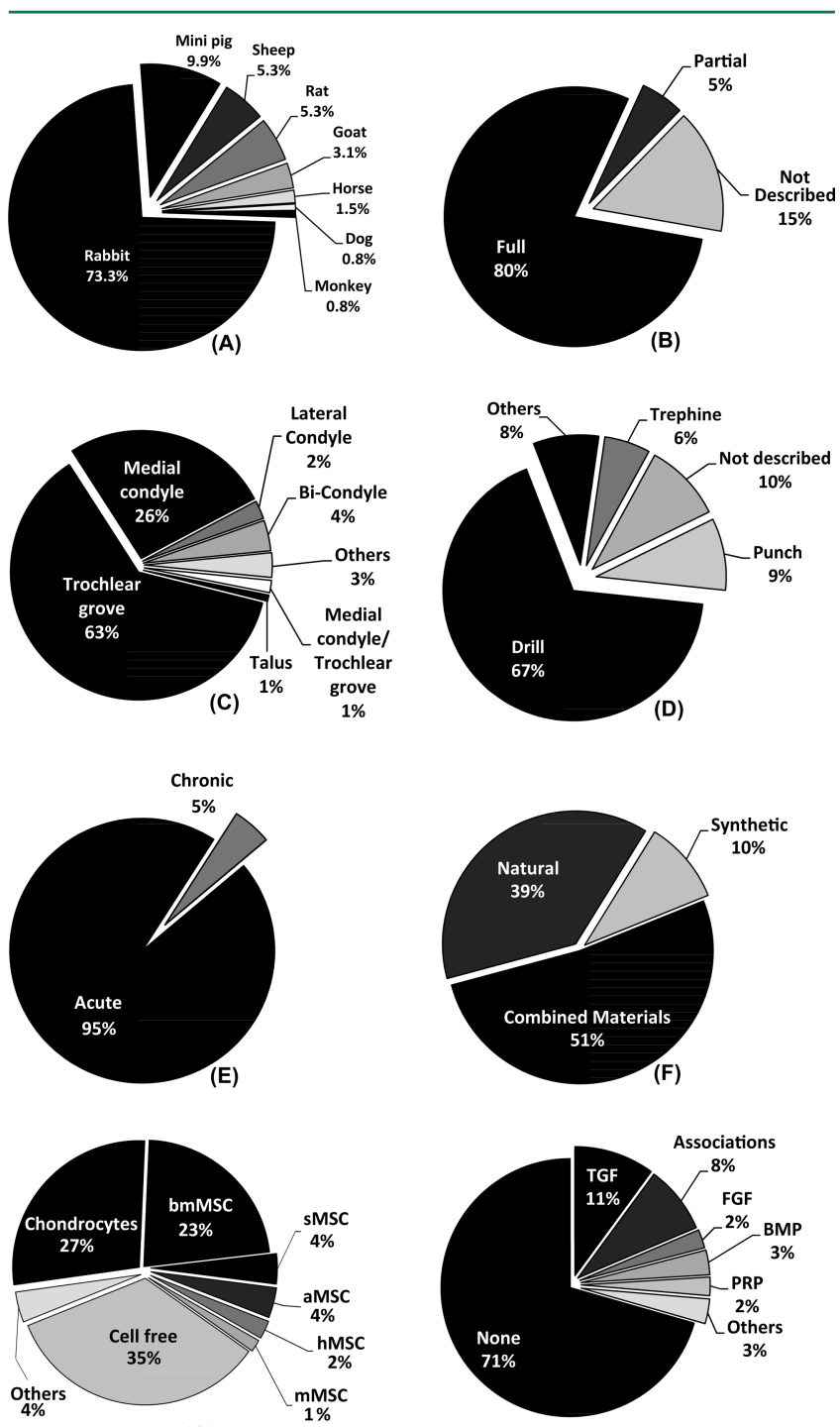

(G) $1 \%$

(H)

Figure 2. Distribution of animal models, characterization of the induced defect and lesion treatment and bioactive agents used: (A) animal model; (B) lesion type; (C) location of the lesion; (D) techniques for defect induction; (E) disease stage; (F) type of scaffold; (G) type of cells: adipose mesenchymal stem cells (aMSC), muscle mesenchymal stem cells (mMSC), synovium mesenchymal stem cells (sMSC), bone-marrow mesenchymal stem cells (bmMSC) and human mesenchymal stem cells (HMSC); $(\mathrm{H})$ growth factors: transforming growth factor (TGF), bone morphogenetic protein (BMP), fibroblast growth factor (FGF), platelet-rich plasma (PRP).

154 cartilage repair by means of using hydrogels, comprising $73.3 \%$ 155 of all studies. Noticeably, other animal models selected for 156 evaluation of hydrogel performance included large animals, 157 such as goat and sheep models, representing 3.1 and $5.3 \%$ of all 158 studies, respectively (Figure 2A). Minipigs were the second 159 animal more frequently used comprising $9.9 \%$ of all studies 160 (Figure 2A).

t1 $161 \quad 3.3 .1$. Age and Weight of Animals. Table 1 summarizes the 162 data regarding age and weight of animals for all the studies 163 analyzed. The absolute ranges depend very much on the animal 164 model. The animal model with the wider age interval was the sheep, with a relative interval of 40-260 weeks. As concerns 165 weight, the animal models with wider weight intervals were 166 sheep and horse, with a relative interval of 22.5 to $80 \mathrm{~kg}$ and 167 307 to $439 \mathrm{~kg}$, respectively.

3.3.2. Number of Animals Per Study. Table 2 presents the 169 t2 number of animals used for each study and the time interval for 170 the time points according to each animal model. The most 171 common number of animals used per study was 12, as this was 172 the mode obtained for mini-pig, rabbit, and sheep models. As 173 for the duration of the studies, 12 weeks was the mode obtained 174 for the most used animal models, rabbit and mini-pig, yet 175 ranging from 4 and 8 to 52 weeks, respectively.

176

3.4. Experimental Protocol. 3.4.1. Type and Geometry of 177 Defects. From Figure 2, it is possible to state that the most 178 frequently induced cartilage defect was a full thickness lesion 179 ( $80 \%$, Figure $2 \mathrm{~B})$, done in the trochlea $(63 \%$, Figure $2 \mathrm{C}$ ) by 180 drilling $(67 \%$, Figure 2D) and treated at an acute stage (95\%, 181 Figure 2E).

Cartilage defect dimensions were also thoroughly analyzed, 183 including area, depth, and volume (Table 3). Most defects had 184 t3 a circular shape, yet 8 articles reported a rectangular or square 185 shape. $^{21-28}$ Therefore, for comparison purposes, it was adopted 186 the defect area to characterize surface dimension. Dimensions 187 varied according to the animal model employed. In general, 188 dimensions of induced cartilage defect were proportional to the 189 size of the animal. For rat, the minimum area of the lesion was 190 $0.6 \mathrm{~mm}^{2}$ and for horse the maximum area was $176.7 \mathrm{~mm}^{2}$. For 191 rabbit, the most frequently adopted animal model, the mode of 192 the lesion area was $7.1 \mathrm{~mm}^{2}$, whereas the lesion area varied 193 between 1.8 and $200 \mathrm{~mm}^{2}$. The very large variation in defect 194 area results from one study where the defect included the 195 complete excision of tibial plateau. ${ }^{29}$

3.4.2. Type of Scaffold. From Figure 2F, it is evident that 197 "combined materials" prevail as the most frequent type of 198 scaffold (51\%). These are composed by two or more materials 199 of either of natural or of synthetic origin. The other types of 200 scaffold that has been mostly investigated were natural derived 201 scaffolds (39\%) and synthetic scaffolds (10\%).

202

When analyzing use of scaffolds with cells, about $65 \%$ of all 203 studies analyzed involved the use of cells, in a so-called 204 combination repair strategy. Nevertheless, about 35\% of 205 cartilage lesions where treated with hydrogels alone (Figure $206 \mathrm{f3}$ $3 \mathrm{~A})$.

3.4.3. Type of Cells. For combination approaches where 208 scaffolds are combined with cells, $27 \%$ of studies used 209 chondrocytes, whereas $38 \%$ used mesenchymal stem cells 210 (Figure 2G). A thorough description of cell types and 211 concentrations used in the analyzed studies are displayed in 212 Table 4. Chondrocytes were the most widely used cell type in a $213 \mathrm{t} 4$ concentration range between $5.00 \times 10^{4}$ and $5.00 \times 10^{7}$ cells/ 214 $\mathrm{mL}$, followed by mesenchymal stem cells (MSC) that have 215 been used in a range between $1.50 \times 10^{5}$ and $7.20 \times 10^{5}$ cells/ 216 $\mathrm{mL}$. We noticed that $35 \%$ of the scaffolds were cell-free. 217

3.4.4. Bioactive Agents. Besides the use of cells with the 218 hydrogels in combination strategies to repair cartilage lesions, 219 growth factors have been also explored to improve quality of 220 regenerated tissue. According to Figure $2 \mathrm{H}$, published papers 221 used at least one growth factor (29\%) for repair of cartilage 222 lesions. Transforming growth factor (TGF) was the most 223 frequent choice, accounting for $11 \%$ of studies, whereas bone 224 morphogenetic protein (BMP) and fibroblast growth factor 225 (FGF) were each used in 3 and $2 \%$ of all studies, respectively. 226 Insulin growth factor (IGF), growth differentiation factor 227 
Table 1. Maximum, Minimum, Average, and Mode of Age and Weight of Animals Used for in Vivo Experiments on Cartilage Repair According to Animal Model As Reported in Analyzed Publications ${ }^{a}$

\begin{tabular}{|c|c|c|c|c|c|c|c|c|}
\hline \multirow[b]{2}{*}{ Animal } & \multicolumn{4}{|c|}{ Age (Weeks) } & \multicolumn{4}{|c|}{ Weight (Kg) } \\
\hline & Max & Min & Avg & Mode & Max & Min & Avg & Mode \\
\hline $\operatorname{dog}^{b}$ & & & 104.0 & & & & 9.4 & \\
\hline goat & & & & & 47.6 & 23.9 & 33.8 & \\
\hline horse & 182 & 156 & 169.0 & & 439.0 & 307.0 & 373.0 & \\
\hline mini pig & 156 & 16 & 43.2 & $24 / 32 / 44$ & 42.0 & 11.0 & 26.2 & 36.5 \\
\hline monkey $^{b}$ & & & 312.0 & & & & 8.0 & \\
\hline rabbit & 96 & 8 & 20.8 & 24 & 4.7 & 1.8 & 3.1 & $2.3 / 3.3$ \\
\hline rat & 12 & 5 & 10.7 & 12 & 0.4 & 0.3 & 0.3 & \\
\hline sheep & 260 & 40 & 152.4 & 117 & 80.0 & 22.5 & 64.9 & $68.0 / 80.0$ \\
\hline
\end{tabular}

Table 2. - Maximum, Minimum, Average, and Mode of the Number of Animals and Duration of Study Adopted for in Vivo Experiments on Cartilage Repair According to Animal Model As Reported in Analyzed Publications ${ }^{a}$

\begin{tabular}{|c|c|c|c|c|c|c|c|c|}
\hline \multirow[b]{2}{*}{ animal } & \multicolumn{4}{|c|}{ no. of animals/paper } & \multicolumn{4}{|c|}{ duration (weeks) } \\
\hline & $\max$ & $\min$ & avg & mode & $\max$ & $\min$ & avg & mode \\
\hline $\operatorname{dog}^{b}$ & & & 9.0 & & & & 10.0 & \\
\hline goat & 20 & 4 & 12.5 & & 24 & 12 & 19.0 & 24 \\
\hline horse & 6 & 6 & 6.0 & & 32 & 24 & 28.0 & \\
\hline mini pig & 27 & 6 & 14.8 & $12 / 16 / 18 / 20$ & 52 & 8 & 20.0 & 1 \\
\hline monkey $^{b}$ & & & 16.0 & & & & 24.0 & \\
\hline rabbit & 81 & 3 & 27.3 & 12 & 52 & 4 & 13.9 & 12 \\
\hline rat & 121 & 9 & 40.2 & & 12 & 4 & 7.0 & \\
\hline sheep & 24 & 3 & 11.4 & $10 / 12$ & 52 & 3 & 27.0 & $16 / 52$ \\
\hline
\end{tabular}

${ }^{a}$ Abbreviations: max, maximum; min, minimum; avg, average. ${ }^{b}$ Only 1 study with this animal model.

Table 3. Maximum, Minimum, Average, and Mode of the Number of Lesions, Lesion Area, Lesion Depth, and Lesion Volume Adopted for in Vivo Experiments on Cartilage Repair According to Animal Model As Reported in Analyzed Publications ${ }^{a}$

\begin{tabular}{|c|c|c|c|c|c|c|c|c|c|c|c|c|c|c|c|c|}
\hline \multirow[b]{2}{*}{ animal } & \multicolumn{4}{|c|}{ no. of lesions } & \multicolumn{4}{|c|}{ lesion area $\left(\mathrm{mm}^{2}\right)$} & \multicolumn{4}{|c|}{ lesion depth (mm) } & \multicolumn{4}{|c|}{ lesion volume $\left(\mathrm{mm}^{3}\right)$} \\
\hline & $\max$ & $\min$ & avg & mode & $\max$ & $\min$ & avg & mode & $\max$ & $\min$ & avg & mode & $\max$ & $\min$ & avg & mode \\
\hline $\operatorname{dog}^{b}$ & & & 2.0 & & & & 19.6 & & & & 4.5 & & & & 88.4 & \\
\hline goat & 2 & 2 & 2.0 & 2 & 28.3 & 19.6 & 24.0 & & 4.0 & 3.0 & 3.3 & 3.0 & 113.1 & 58.9 & 78.9 & 58.9 \\
\hline horse & 2 & 2 & 2.0 & & 176.7 & 176.7 & 176.7 & & 2.8 & 2.8 & 2.8 & & 486.0 & 486.0 & 486.0 & \\
\hline mini pig & 8 & 1 & 2.8 & 2 & 56.7 & 12.6 & 32.3 & 28.3 & 6.0 & 1.0 & 2.6 & $1.0 / 3.0$ & 169.6 & 28.3 & 87.1 & 28.3 \\
\hline monkey $^{b}$ & & & 2.0 & & & & 7.1 & & & & 5.0 & & & & 35.3 & \\
\hline rabbit & 6 & 1 & 2.1 & 2 & 200.0 & 1.8 & 15.4 & 7.1 & 15.0 & 0.5 & 3.7 & 3.0 & 217.8 & 3.5 & 51.0 & 21.2 \\
\hline rat & 2 & 1 & 1.5 & 1 & 3.1 & 0.6 & 1.9 & 1.8 & 2.0 & 1.0 & 1.5 & & 6.3 & 1.8 & 3.3 & \\
\hline sheep & 12 & 1 & 5.0 & 4 & 50.3 & 8.0 & 32.4 & $28.3 / 38.5$ & 12.0 & 2.0 & 6.7 & 12.0 & 423.1 & 32.2 & 205.5 & $77.0 / 339.3$ \\
\hline
\end{tabular}

${ }^{a}$ Abbreviations: max, maximum; min, minimum; avg, average. ${ }^{b}$ Only 1 study with this animal model.

${ }_{228}$ (GDF), connective tissue growth factor (CTGF), and Nel-like 229 molecule-1 (NELL-1) account for a total of 3\% of studies 230 (Figure $2 \mathrm{H}$ ). Noticeably, platelet-rich plasma (PRP) has also 231 considerable expression in this context, accounting for $2 \%$ of all 232 studies (Figure $2 \mathrm{H}$ ).

233 3.4.5. Time Points and Study Groups. Table 5 presents 234 number of time points, number of study groups, and number of 235 lesions per study group for the analyzed publications. 236 Concerning the number of time points, the majority of studies 237 included at least 2 time points, yet the number ranged from 1 238 time point up to 7 time points. Three study groups was the 239 most common among all animal models, yet the number of 240 lesions per study group averaged $12-15.4$, for the mini-pig and 241 rabbit models, respectively.

242 For all animal models, the number of study groups was 243 between 2 and 9. Concerning the number of lesions by study 244 group $(N)$, this index was calculated according the equation:

$$
N=\frac{\text { no. of animals } \times \text { no. of lesions by animal }}{\text { no. of study groups }}
$$

According to Table 5, the number of lesions per study groups 245 was between 3 and 74.0.

246

3.4.6. Characterization of Cartilage Repair. Several 247 techniques have been used to evaluate regeneration of cartilage 248 tissue within the induced lesions. Histological staining of 249 cartilage explants were done in all studies, including 250 hematoxylin and eosin staining in most of the studies, 251 complemented with at least one of the following: alcian blue, 252 toluidine blue, safranin $\mathrm{O}$, and/or Masson's trichrome staining. 253 Immunohistochemistry staining, commonly used for identi- 254 fication of collagen type II and/or collagen type I, were done in 255 71 reports. For histological evaluation several histological scores 256 were chosen: O'Driscoll, Pineda, ICRS, Mankin, Moran, 257 Wakitani, Wayne, Selleŕs, Caplan, and Susante. In 15 papers, 258 two of the previous scores were used simultaneously. O'Driscoll 259 
A)
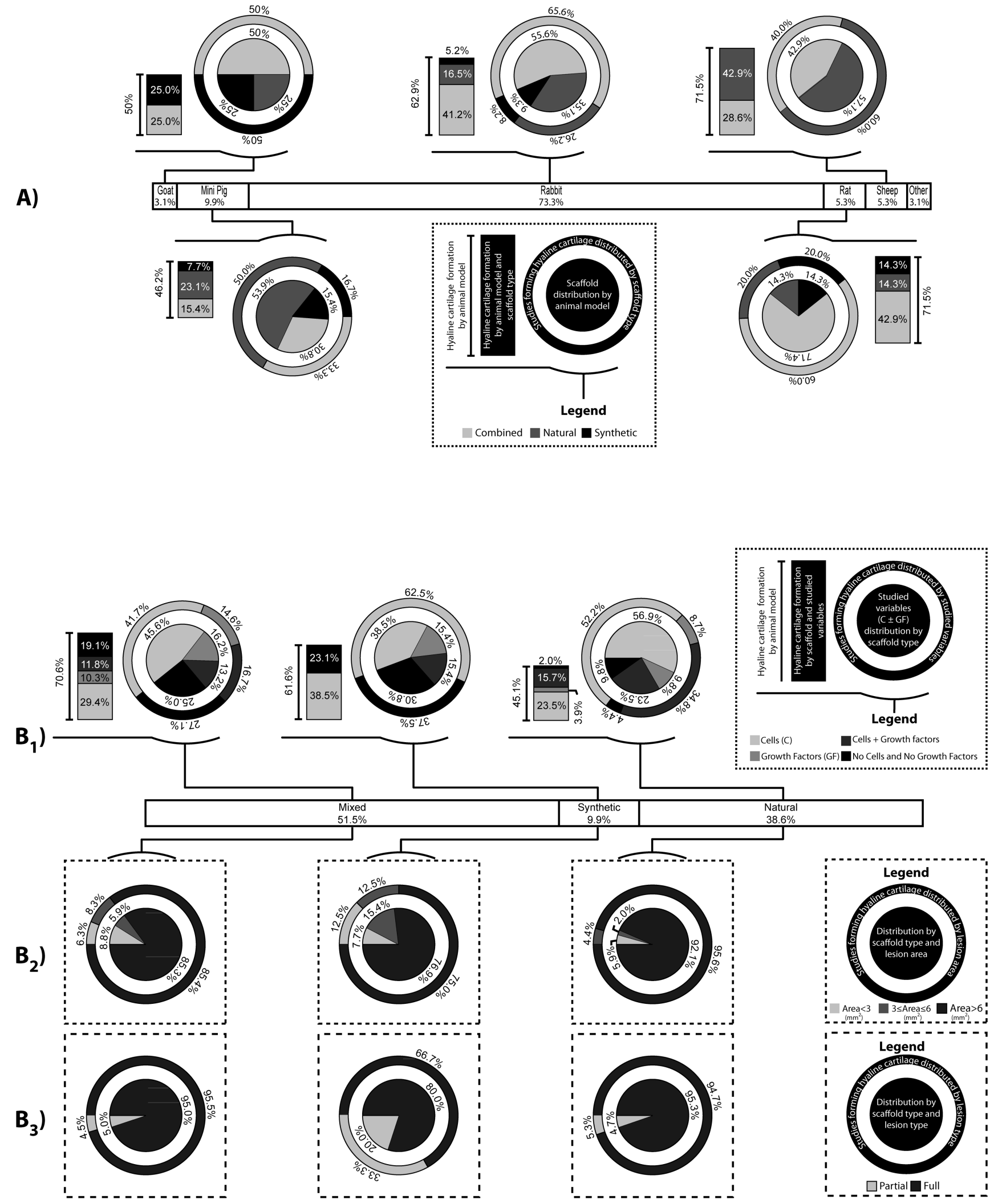

Figure 3. Correlation of data variables. (A) Inner circle: distribution of scaffold type used in each animal model; outer circle: efficacy of each scaffold type in forming hyaline cartilage. Lateral column displays overall efficacy of the animal model in yielding hyaline cartilage outcomes, further discriminated by scaffold type. (B1) Inner circle: distribution of cell \pm growth factors used in each scaffold type; outer circle: efficacy of each cell \pm growth factor combination in forming hyaline cartilage. Lateral column displays overall efficacy of scaffold type in yielding hyaline cartilage outcomes, further discriminated by cell \pm growth factor combination. (B2) Inner circle: distribution of lesion area used in each scaffold type; outer circle: efficacy of lesion area in yielding hyaline cartilage outcomes. (B3) Inner circle: distribution of lesion type used in each scaffold type; outer circle: efficacy of lesion type in yielding hyaline cartilage outcomes. 
Table 4. Maximum, Minimum, and Average Number of Cells Used for in Vivo Experiments on Cartilage Repair According to Cell Type and Animal Model As Reported in Analyzed Publications ${ }^{a}$

\begin{tabular}{|c|c|c|c|c|c|c|c|c|c|}
\hline \multirow[b]{2}{*}{ cell type } & \multirow[b]{2}{*}{$\begin{array}{c}\text { cell } \\
\text { concentration } \\
(\text { cells } / \mathrm{mL})\end{array}$} & \multicolumn{8}{|c|}{ animal } \\
\hline & & $\operatorname{dog}^{b}$ & goat & horse & mini pig & monkey $^{b}$ & rabbit & rat & sheep \\
\hline \multirow[t]{3}{*}{ aMsc } & $\max$ & & & & & & $1.50 \times 10^{07}$ & $1.00 \times 10^{06}$ & \\
\hline & $\min$ & & & & & & $1.00 \times 10^{06}$ & $1.00 \times 10^{06}$ & \\
\hline & avg & & & & & & $9.00 \times 10^{06}$ & $1.00 \times 10^{06}$ & \\
\hline \multirow[t]{3}{*}{ bMsc } & $\max$ & & $5.00 \times 10^{07}$ & & $7.00 \times 10^{06}$ & $1.00 \times 10^{06}$ & $5.00 \times 10^{07}$ & & $7.20 \times 10^{05}$ \\
\hline & $\min$ & & $5.00 \times 10^{07}$ & & $1.00 \times 10^{05}$ & $1.00 \times 10^{06}$ & $1.50 \times 10^{05}$ & & $4.00 \times 10^{05}$ \\
\hline & avg & $1.00 \times 10^{07}$ & $5.00 \times 10^{07}$ & & $2.28 \times 10^{06}$ & $1.00 \times 10^{06}$ & $1.28 \times 10^{07}$ & & $5.07 \times 10^{05}$ \\
\hline \multirow[t]{3}{*}{$\mathrm{BNC}$} & $\max$ & & & & $1.00 \times 10^{05}$ & & & & \\
\hline & $\min$ & & & & $1.00 \times 10^{05}$ & & & & \\
\hline & avg & & & & $1.00 \times 10^{05}$ & & & & \\
\hline \multirow[t]{3}{*}{ chondrocytes } & $\max$ & & $5.00 \times 10^{06}$ & & $5.00 \times 10^{07}$ & & $5.00 \times 10^{07}$ & $5.00 \times 10^{04}$ & $4.00 \times 10^{07}$ \\
\hline & $\min$ & & $1.00 \times 10^{06}$ & & $2.00 \times 10^{05}$ & & $7.50 \times 10^{04}$ & $5.00 \times 10^{04}$ & $1.00 \times 10^{06}$ \\
\hline & avg & - & $3.00 \times 10^{06}$ & $1.20 \times 10^{07}$ & $1.59 \times 10^{07}$ & & $5.76 \times 10^{06}$ & $5.00 \times 10^{04}$ & $1.63 \times 10^{07}$ \\
\hline \multirow[t]{3}{*}{ HMsc } & $\max$ & & & & & & $1.00 \times 10^{06}$ & $2.00 \times 10^{07}$ & \\
\hline & $\min$ & & & & & & $1.00 \times 10^{06}$ & $2.00 \times 10^{07}$ & \\
\hline & avg & & & & & & $1.00 \times 10^{06}$ & $2.00 \times 10^{07}$ & \\
\hline \multirow[t]{3}{*}{$\mathrm{mMsc}$} & $\max$ & & & & & & $2.00 \times 10^{06}$ & & \\
\hline & $\min$ & & & & & & $1.00 \times 10^{06}$ & & \\
\hline & avg & & & & & & $1.50 \times 10^{06}$ & & \\
\hline \multirow[t]{3}{*}{ PBC } & $\max$ & & & & & & $2.36 \times 10^{07}$ & & \\
\hline & $\min$ & & & & & & $2.36 \times 10^{07}$ & & \\
\hline & avg & & & & & & $2.36 \times 10^{07}$ & & \\
\hline \multirow[t]{3}{*}{ periostal cells } & $\max$ & & & & & & & & $8.00 \times 10^{06}$ \\
\hline & $\min$ & & & & & & & & $8.00 \times 10^{06}$ \\
\hline & avg & & & & & & & & $8.00 \times 10^{06}$ \\
\hline \multirow[t]{3}{*}{ sMsc } & $\max$ & & & & & & $1.00 \times 10^{08}$ & & \\
\hline & $\min$ & & & & & & $1.00 \times 10^{06}$ & & \\
\hline & avg & & & & & & $3.82 \times 10^{07}$ & & \\
\hline
\end{tabular}

aMSC: adipose mesenchymal stem cells; bmMSC: bone-marrow mesenchymal stem cells; bmNC: bone-marrow nucleated cells; HMSC: human mesenchymal stem cells; mMSC: muscle mesenchymal stem cells; PBC: peripheral blood mononuclear cells; sMSC: synovium mesenchymal stem cells; max, maximum; min, minimum; avg, average. ${ }^{b}$ Only 1 study with this animal model.

Table 5. Maximum, Minimum, Average, and Mode of the Number of Time Points, Number of Study Groups, and Number of Lesions Per Study Group Adopted for in Vivo Experiments on Cartilage Repair According to Animal Model As Reported in Analyzed Publications

\begin{tabular}{|c|c|c|c|c|c|c|c|c|c|c|c|}
\hline \multirow[b]{2}{*}{ animal } & \multicolumn{4}{|c|}{ no. of time points } & \multicolumn{4}{|c|}{ no. of study groups } & \multicolumn{3}{|c|}{ no. of lesions/study group } \\
\hline & $\max$ & $\min$ & avg & mode & $\max$ & $\min$ & avg & mode & $\max$ & $\min$ & avg \\
\hline $\operatorname{dog}^{a}$ & & & 2.0 & & & & 2.0 & & 9 & 9 & 9.0 \\
\hline goat & 3 & 1 & 2.0 & 2 & 4 & 2 & 3.0 & 3 & 12 & 3 & 8.3 \\
\hline horse & 2 & 1 & 1.5 & & 2 & 2 & 2.0 & & 6 & 6 & 6.0 \\
\hline mini pig & 3 & 1 & 1.5 & 1 & 5 & 2 & 3.1 & 3 & 24 & 5 & 12.0 \\
\hline monkey $^{a}$ & & & 3.0 & & & & 2.0 & & & & 16.0 \\
\hline rabbit & 7 & 1 & 2.3 & 2 & 9 & 2 & 3.3 & 3 & 74 & 3 & 15.4 \\
\hline rat & 3 & 1 & 1.8 & 1 & 7 & 3 & 3.9 & 3 & 20 & 13 & 16.8 \\
\hline sheep & 3 & 1 & 1.7 & $1 / 2$ & 6 & 2 & 3.9 & 4 & 20 & 6 & 10.8 \\
\hline
\end{tabular}

260 scoring was used, alone or combined with another score, in 29 261 publications, followed by Wakitani scoring in 20 studies and by 262 the ICRS scoring in 19 papers. In 32 studies, no histological 263 score was used to evaluate the quality of cartilage regeneration. 264 As outcome of histological evaluation, most studies have 265 obtained statistically significant improvement in cartilage 266 regeneration for treated groups as compared to control groups. 267 In 3 papers, ${ }^{30-32}$ no significant histological improvement was 268 observed between treated and untreated groups, and in 4 papers, $^{33-36}$ no histological differences were found between 269 study groups. Most studies reported on the development of 270 hyaline-like cartilage, while 8 studies $^{37-44}$ reported no cartilage 271 like tissue or a mixture of fibrous cartilage and hyaline-like 272 cartilage in the repaired tissue. In 14 studies, ${ }^{23,30-32,45-51}$ the 273 repair tissue was not classified as hyaline-like cartilage. In $5_{274}$ papers, ${ }^{21,52-54}$ a tendency for deterioration of cartilage tissue 275 along time was reported. 
277 Quantitatively, gene expression was evaluated in 25 studies $278(21,7 \%)$. Characterization of mechanical performance of 279 regenerated tissue was highly uncommon, as it was performed 280 in 8 studies. Imaging evaluation including magnetic resonance 281 imaging (MRI), microcomputed tomography ( $\mu$-CT), laser 282 scanning arthroscopy, and optical coherence tomography 283 (OCT) was performed in 19 studies.

284 3.4.7. Side Effects. Several side effects have been reported in 285 the studies analyzed such as inflammation, degeneration, tissue 286 hypertrophy, among others. No information was given related 287 to this issue in 26 studies. Inflammatory response was reported 288 in 9 studies, ${ }^{24,31,52,55-60}$ including, synovitis, fibrosis, and 289 fissures. By its turn, 13 papers reported degenerative or 290 pathological changes like osteophytes, cyst formation, or bone 291 hypertrophy. In these studies, one of the following were used: a 292 periostal flap in a chondrocyte cell-laden scaffold, ${ }^{21}$ PRPs, $^{61}$ a 293 growth factor (TGF $\beta,{ }^{62,63} \mathrm{BMP}-2,{ }^{31} \mathrm{FGF}^{52}$ ), or cells (ASC, ${ }^{64}$ 294 BMSC, $^{65}$ MSC, $^{25,54}$ chondrocytes ${ }^{66}$ chondrocytes/periostal 295 cells $^{67}$ ). In another study, ${ }^{68}$ the control group developed a 296 degenerative change.

\section{DISCUSSION}

297 The present systematic review revealed that hydrogels used for 298 cartilage repair include those composed by single natural or 299 synthetic biomaterials, or by combination of these, designated 300 as "combined materials" (Figure 2F). Advantages/disadvan301 tages of natural and synthetic biomaterials for cartilage repair 302 are detailed elsewhere. ${ }^{69,70}$ Among the literature revised, 39\% of 303 studies proposed natural materials including colla304 gen, $21,22,25,26,28,32,39,47,50,52,58,63,64,71-76$ algi305 nate, ${ }^{37,38,40,48,62,77-80}$ fibrin, ${ }^{29,33,81,82}$ platelet-rich plasma, ${ }^{6,83}$ 306 hyaluronic acid, ${ }^{27,31,57,84,85}$ gellan gum, ${ }^{86}$ chitosan, ${ }^{42,87}$ and 307 sugar cane biopolymer. ${ }^{88}$ For $10 \%$ of studies, synthetic 308 materials included oligo(poly(ethylene glycol) fumarate) 309 (OPF), ${ }^{43,46,89}$ poly $(N$-isopropylacrylamide-co-acrylic acid) 310 (poly(NiPAAm-co-AAc)), ${ }^{90}$ poly(L-lactide-co-3-caprolactone) 311 (PLCL), ${ }^{91,92}$ Si-HPMC, ${ }^{36}$ polypeptides, ${ }^{35,65,93}$ and $\alpha$-CD-EG $3124400 .^{94}$ The scaffolds using combined materials were composed 313 by two or more natural materials, representing $51 \%$ of the 314 studies, ${ }^{17-19,49,60,66-68,95-100}$ by association of two or more 315 synthetic polymers, ${ }^{101-109}$ by the association of natural 316 materials with a synthetic polymer, ${ }^{20,23,44,45,51,54-56,59,76,110-128}$ 317128 by association of others materials. ${ }^{24,30,34,41,53,129-132}$ When 318 analyzing Table 6, it is clear that most biomaterials succeed (to 319 a higher or less extent) on regenerating hyaline matrix, while 320 delivering bioactive agents such as cells and/or growth factors, 321 as well as fulfilling fundamental requirements for translation 322 into human scenario. Major limitations of these gels/hydrogels 323 relate to unsatisfactory mechanical properties, capable to 324 immediately withstand load after treatment, as well as a 325 mismatch of biomaterial degradation rate as compared to tissue 326 regeneration (either too fast or to slow). The combination of 327 the hydrogel with a rigid scaffold has been tested (for example 328 PLCL, ${ }^{23}$ PLA/PLGA, ${ }^{92}$ aiming to improve mechanical proper329 ties, whereas the downside relates to loss of injectability, and 330 consequently, adequacy of the system to be delivered by a 331 minimally invasive approach. Cross-linking mechanisms differ 332 among the biomaterial types, yet can be used, to a certain 333 extent, to fine-tune mechanical properties as well as degradation 334 rate of the hydrogels. Not less important in the cartilage repair 335 equation, is the capacity to mimic the complex layered structure 336 of articular cartilage tissue. Although current gels and hydrogels 337 are still limited in this regard, future developments in the

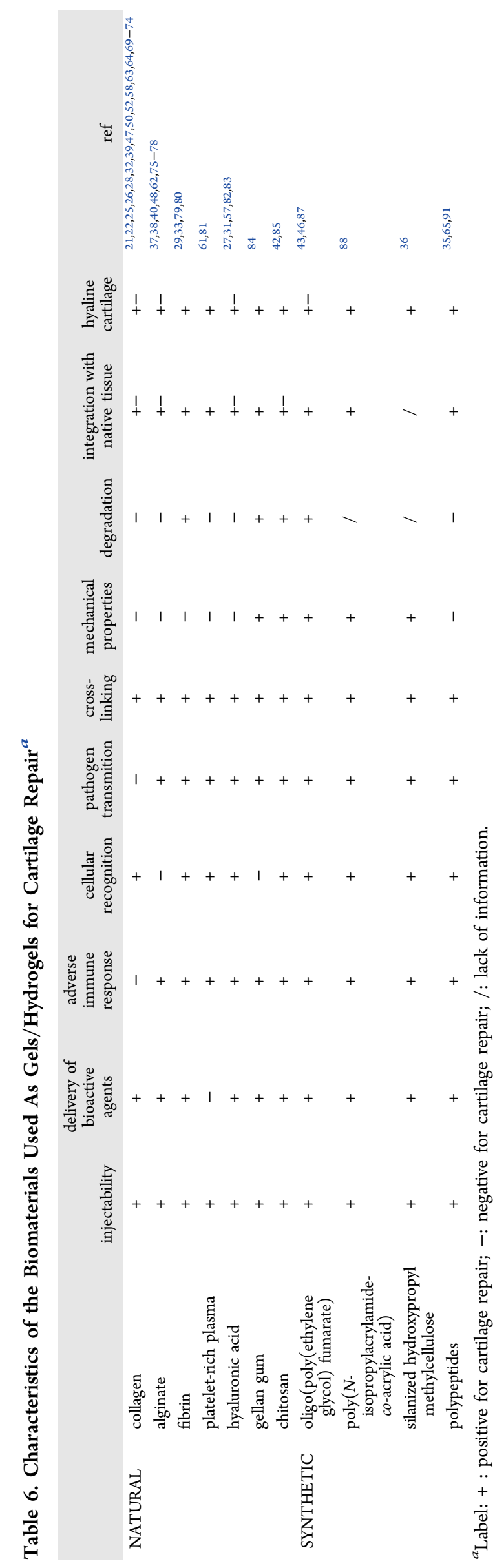


338 biomaterials field might pursue this target, by providing more 339 sophisticated, smart, and multifunctional materials for improved 340 cartilage regeneration. ${ }^{133,134}$

341 Regarding the animal model used, the rabbit was the 342 preferred, comprising $73.3 \%$ of all studies. Rabbits gather 343 several features that make it an attractive model for cartilage 344 regeneration research. It is of easy handling, caging. and care, 345 has a good cost effectiveness and enough dimensions of the 346 trochlear groove and condyles for the induction of a 3-4 mm 347 diameter cartilage defects. ${ }^{135}$ However, the relatively thin 348 cartilage thickness (approximately $0.4 \pm 0.1 \mathrm{~mm}$ in the 349 trochlear groove), ${ }^{136}$ has limited the volume size of the 350 cartilage defect. ${ }^{135}$ Another limitation of this animal model is 351 the high degree of the rabbit knee flexion, creating a partial 352 weight-bearing condition when the trochlear groove is chosen 353 as location for cartilage defect induction/repair. ${ }^{137}$ The present 354 review revealed that the majority of studies used were immature 355 rabbits younger than 8 months, the minimum age considered 356 for maturity of rabbits. ${ }^{138}$ The above-mentioned disadvantages 357 and the high potential of the rabbit model for spontaneous 358 healing, ${ }^{84,139}$ especially in immature animals, are important 359 limitations to address when the rabbit is used as a translational 360 model to human knee cartilage. Herein, it was noticed a 361 progressive use of larger and more weighted animal models, 362 allowing bigger cartilage defects that reproduce better the size, 363 depth, and conditions of human cartilage lesions. ${ }^{135}$ Fur364 thermore, some of these models, as opposed to rabbit, have a 365 low spontaneous cartilage repair ability, ${ }^{140-142}$ and similr to 366 humans, suffer from osteochondritis dissecans and osteo367 arthritis pathologies. ${ }^{135}$

368 An articular cartilage defect is classified as full or partial369 thickness defect according to the penetration into the 370 subchondral bone. ${ }^{116,143}$ Considering the known cartilage 371 thickness of the different animal models, ${ }^{135,144}$ the majority of 372 the defects overviewed in this review are deeper than the 373 expected cartilage thickness for those models, therefore, these 374 were classified as full-thickness defects or as osteochondral 375 defect. This is a very important drawback regarding the 376 relevance of the models used for evaluation of cartilage repair 377 performance, given that in humans superficial cartilage lesions 378 are the most common, and only 5\% are osteochondral defects. ${ }^{3}$ 379 Most of the studies have reported the treatment of cartilage 380 defects at an acute stage. From the total publications analyzed, 381 only 6 were related to chronic stages of the cartilage 382 defect. $^{34,63,64,75,111,113}$ It is recognized that a chronic cartilage 383 lesion is a diverse condition as compared to an acute cartilage 384 lesion. $^{26,34,145}$ This fact highlights the importance of addressing 385 the correct stage of lesion progression in animal models when 386 translating to human treatment.

387 As for tissue characterization, the majority of the studies 388 included immunohistochemical evaluation of the neo-cartilage 389 by evaluating the presence of collagen type I and type II, 390 whereas expression of type $\mathrm{X}$ was determined in only 3 391 studies. ${ }^{19,115,132}$ It is important to identify the expression of 392 collagen type $\mathrm{X}$, in order to exclude the possibility of 393 hypertrophic tissue development or a transient cartilage. ${ }^{64}$

394 Determination of gene expression was performed in 24 395 studies. In these, an increase in cartilage-related gene expression 396 was found in the regenerated tissue. Nevertheless, given the 397 mismatch of information regarding gene expression, it is not 398 possible to perform a full comparison between studies.

399 Assessment of mechanical performance of the new tissue is a 400 relevant dimension when evaluating quality of the cartilage repair. Yet, its implementation is difficult, as it depends on 401 anatomical location, measurement methodology and specific 402 conditions of the joint. ${ }^{66}$ The mechanical properties of the 403 repaired tissue were evaluated in only 8 studies. In most of 404 these, properties of the new tissue were similar or close to 405 native cartilage. ${ }^{24,32,34,77,114}$ Some authors found inconsistent 406 results $^{75}$ and repaired tissue showed a higher stiffness as 407 compared to normal cartilage. ${ }^{24,94}$ As expected, similar 408 mechanical properties between repaired tissue and normal 409 cartilage was correlated with regenerated hyaline-like cartilage, 410 except for the study by Pulkkinen et al., ${ }^{32}$ which despite 411 mechanical properties being similar to native cartilage, the 412 repaired tissue did not correspond histologically to hyaline-like 413 cartilage. From these studies, two main issues can be 414 highlighted: (i) large variety of reported methodologies 415 among studies for determining mechanical performance of 416 regenerated cartilage; (ii) adopted methodologies that do not 417 reflect natural physiological condition. ${ }^{66}$ These issues pose 418 additional challenges when assessing quality of the regenerated 419 cartilage in animal models using new biomaterial/therapeutic 420 candidates, and when translating such performance during 421 proof-of-concept or preclinical setting, to human performance 422 in clinical setting.

The majority of the studies did not compare the treatment 424 groups with reference treatments, adopted as clinical standard, 425 such as microfracture or osteochondral grafting, which would 426 be of high value to infer the relative efficacy of the new 427 biomaterial/therapeutic candidates. For full-thickness defects 428 (the most frequent defect type studied), the nontreated control 429 group acts in a similar way to microfracture as there is exposure 430 to bone marrow. Yet, for partial-thickness defect, only 1 study 431 compared the outcome with microfracture treatment. ${ }^{86} 432$ Concerning osteochondral grafting, only 2 studies compared 433 the results of between scaffold treated groups with osteochon- 434 dral grafting. ${ }^{34,48}$

Regarding the use of cells, most studies used chondrocytes, 436 although mesenchymal stem cells (MSC) have been also highly 437 explored. $^{39}$ Adipose mesenchymal stem cells (aMSC), muscle 438 mesenchymal stem cells (mMSC), synovium mesenchymal 439 stem cells (sMSC), and bone-marrow mesenchymal stem cells 440 (bmMSC) were used, which avoid donor site morbidity in the 441 cartilage tissue. Among the different stem cell sources, it was 442 stated that sMSC and bmMSC show a greater chondrogenic 443 potential as compared to aMSC or mMSC, while one study 444 reported, in addition, greater proliferation potential of sMSC. ${ }^{28} 445$ Many researchers have reported an improvement in bone and 446 cartilage formation ${ }^{39,59}$ when MSC were implanted. These 447 improvements were promising, with a superior cartilage 448 bonding to adjacent native cartilage, when compared with 449 articular chondrocytes. ${ }^{64}$ However, some authors ${ }^{44,50,54,121}$ did 450 not find better results in cartilage regeneration when MSCs 451 were used.

Regarding the the use of growth factors, a relationship 453 between use of growth factors and inflammatory response or 454 pathological changes, was not found. However, reported 455 responses were identified in only 5 experiments that have 456 used growth factors. $^{24,31,62,63,65}$ For 1 case using BMP-2, 457 extensive ectopic bone formation was observed. ${ }^{31} 458$

TGF- $\beta$ seems to be dose-dependent and lower concen- 459 trations are more effective in repairing cartilage defects and 460 decrease osteophyte formation. ${ }^{62}$ TGF- $\beta 1$ has been suggested 461 to have a pro-inflammatory response, but no study using TGF- 462 $\beta 1$ reported an inflammatory response. TGF- $\beta 1$ promoted 463 
464 trabecular bone subchondral appearance but did not improve 465 cartilage cell morphology or glycosaminoglycan (GAG) 466 expression, ${ }^{44}$ while TGF- $\beta 3$ was suggested to have a chemo467 tactic cue for cell homing. ${ }^{114}$ The combination of BMP-7 and 468 TGF- $\beta 1$ was found to induce chondrogenic differentiation. ${ }^{115}$ 469 To be considered mature hyaline cartilage, the repaired tissue 470 must exhibit normal morphology of chondrocytes and normal 471 safranin $O$ staining and possess an adequate structural 472 organization with vertical columnar alignment of chondrocytes. 473 When the last condition is not attained, the repair tissue is 474 classified as immature. If the tissue is composed of dense 475 spindle-shaped fibroblasts, the tissue is graded as fibrous tissue. 476 When the repair tissue contains cells beginning to differentiate 477 toward chondrocytes, the tissue is called as undifferentiated 478 mesenchymal tissue. ${ }^{48,146}$ Another important aspect is that 3 479 studies did not obtain statistically significant improvement in 480 treated groups when compared with untreated group. ${ }^{30-32}$ 481 Although the majority of studies reported improvement of 482 cartilage regeneration in treated groups, 22 studies did not 483 recognize formation of hyaline-like cartilage at the repaired 484 defect site. Therefore, better scoring of repaired tissue does not 485 mean necessarily hyaline-like cartilage formation. Further 486 discussion might focus on reliability and adequacy of scores 487 used to evaluate regenerated cartilage tissue. Bonasia et al, 488 tested the inter- and intraobserver reliability of 10 scores and 489 concluded that, for evaluation of cartilage repair in animal 490 models, the ICRS II, O'Driscoll and modified O'Driscoll scores 491 are preferential given their high reliability, and the fact that the 492 whole joint is available for histological assessment. ${ }^{147}$ On the 493 other hand, for evaluation of human cartilage biopsies, the 494 ICRS I or II or Oswestry score are preferable given the limited 495 tissue available. ${ }^{147}$

496 The studies analyzed herein evaluated repaired tissue mostly 497 by the O'Driscoll score, followed by the Wakitani. One of the 498 limitations of these scores relate to the lack of validation by 499 biochemical analysis. ${ }^{148}$ Only the Bern score has undergone 500 such validation, yet has been considered more adequate for 501 analysis of tissue-engineered constructs ${ }^{148}$ instead of repair of 502 cartilage in animal models. Accordingly, it was not used in any 503 of the revised studies. For the O' Driscoll score, safranin O 504 staining grading is not reflected in the final score and a limited 505 difference was observed between a "moderate" and a "poor" 506 quality of regenerated cartilage. ${ }^{148}$ Although the O' Driscoll 507 score includes evaluation of repaired tissue structure, it does 508 not consider other parameters such as mineral degeneration, 509 vascularity, subchondral bone, viability cell population, 510 inflammation, and cartilage plug quality. ${ }^{148}$ As previously 511 reported, ${ }^{149}$ evaluation of cartilage repair should make use of 512 more than one score, complemented by biochemical, 513 automated histomorphometry, and biomechanical correlation.

514 Data Correlation. Given the above-mentioned compilation 515 of data, one would be tempted to understand which 516 combination of factors would seem the most promising in 517 yielding regeneration of cartilage tissue. Despite the high 518 number of variables and possible combinations, an excel VBA 519 application was developed in order to correlate data. Studies 520 were characterized as "hyaline" or "no hyaline" based on the 521 studies' author classification of repaired tissue. Subsequently, 522 studies were selected based on the use or no use of cells (C) 523 and/or growth factors (GF), by animal model or lesion size, 524 ultimately correlated by type of scaffold (natural, synthetic, or 525 combined materials). Outcomes are displayed in Figure 3.
Regarding the animal model (Figure 3A), despite the rabbit 526 not being recommended as a model to evaluate cartilage repair 527 due to small cartilage thickness, and high spontaneous 528 regeneration, ${ }^{150,151}$ when analyzing Figure 3A, it is evident 529 that among all animal models, the rabbit has been the most 530 widely used, comprising $73.3 \%$ of all studies. Of these, $62.9 \% 531$ claimed to have generated hyaline-like cartilage tissue. 532 Apparently, combined scaffolds were responsible for such 533 outcome, comprising $41.2 \%$ of the hyaline repaired tissue. 534 Nevertheless, for bigger animal models (goat, sheep, and mini 535 pig), the natural origin scaffolds seem to result in superior 536 hyaline-like cartilage regeneration, as compared to those using 537 combined or synthetic hydrogels.

538

When analyzing from another perspective, it was possible to 539 determine that $55.6 \%$ of all rabbit studies used combined 540 scaffolds, and these generated $65.6 \%$ of all hyaline-positive 541 outcomes. This trend is maintained for all animal models, 542 whereas the synthetic scaffolds seem to yield inferior outcomes. 543

Figure 3B1 displays an analysis of the combination of cells 544 (C) and/or growth factors (GF) with the different types of 545 hydrogels, and their synergistic effect on cartilage repair. In fact, 546 of all studies analyzed, $51.5 \%$ used hydrogels composed of 547 combined materials and resulted in a $70.6 \%$ success rate on 548 generating hyaline-like cartilage. Those using scaffolds of 549 natural origin (38.6\%) seem less successful, where only $45.1 \% 550$ generated hyaline regeneration. Nevertheless, it does seem that 551 the presence of cells generally improve probability of successful 552 regeneration of tissue, as major percentage of successful 553 outcomes where achieved through the use of cells in 554 combination with the scaffold, while the positive effect of the 555 presence of growth factors is not so evident (Figure 3B1). $\quad 556$

An additional correlation factor was lesion size, where type of 557 scaffold (natural, synthetic or combined), was related to the 558 lesion area $\left(<3 \mathrm{~mm}^{2}, 3-6 \mathrm{~mm}^{2}\right.$, or $\left.>6 \mathrm{~mm}^{2}\right)$ and relative 559 percentage of incidence on generating hyaline cartilage was 560 analyzed (Figure 3B2). Overall, hydrogels of combined 561 materials seem to perform better than natural or synthetic 562 hydrogels, in nearly all dimension ranges, yet it seems that for 563 larger lesions, natural origin hydrogels provided better 564 outcomes.

On what regards deepness of lesion (Figure 3B3), full- 566 thickness was the most used and the most successful in 567 obtaining hyaline cartilage, according to their authors. 568 However, interpretation of this outcome is limited to the 569 reduced number of studies that have tested repair of partial 570 lesions (only $5 \%$ of all studies).

Study Limitations Acknowledged by Authors. Some authors pointed several limitations in their studies: the 573 dimension of the sample $27,30,34,39,67,103,43,108$ and specific 574 problems with design of the study. ${ }^{44,65,96,101,102}$ In addition, 575 several limitations have been pointed out, such as lack of 576 biomechanical evaluation, ${ }^{28,67,99,104-106,112,129,131}$ short follow- 577 up $^{27,43,62,77,101,103,105,106,109,113,122,130,131}$ animal immaturity, 578 and type of animal model, ${ }^{77,104,105,110,117}$ poor representative- 579 ness of human pathology, ${ }^{93}$ origin-cell identification not 580 possible in the majority of the studies, ${ }^{25,26,67,131}$ absence of a 581 specific rehabilitation program, ${ }^{113}$ and experimentation under 582 no load bearing conditions. ${ }^{34,106}$ The International Cartilage 583 Repair Society (ICRS) $)^{150}$ and the American Society for Testing 584 and Materials (ASTM) ${ }^{151}$ have published guidelines and 585 recommendations for preclinical studies aiming cartilage repair, 586 that could be considered by researchers in order to generate 587 valuable and comparable data, ultimately contributing to 588 
589 stronger advancement of knowledge in the field of cartilage 590 repair.

\section{CONCLUSIONS}

591 In summary, hydrogel biomaterials seem to be promising 592 candidates for cartilage repair, given that hyaline-like cartilage 593 development was proved in a considerable number of studies. A 594 potential advantage of using hydrogels for cartilage repair is its 595 suitability for arthroscopic delivery, yet, in many studies, 596 hydrogel properties did not seem compatible with this 597 minimally invasive approach. Overall, further development on 598 surgical technique will be required.

599 The majority of the published papers addressed small, acute 600 and a full-thickness cartilage defect in a nonweight bearing area. 601 These conditions are very different from those found in human 602 patients which is a concerning limitation considering translation 603 of experimental learnings toward human treatment. The need 604 for animal models and experimental designs that consider those 605 aspects is obvious and must be considered in future animal 606 experimentation studies.

607 In addition, anticipation of potential therapeutic efficacy in 608 human demands a more conclusive mechanical evaluation of 609 the regenerated tissue, as well as long-term studies. Not less 610 important is the need of standardization of the evaluation 611 procedures, especially on what concerns histology in order to 612 enable comparison among different studies. The use of uniform 613 guidelines for the definition of the general conditions and 614 techniques to be used in cartilage repair experiments is 615 mandatory to ensure comparability of studies.

\section{AUTHOR INFORMATION}

\section{Corresponding Author}

618 *E-mail: rgreis@dep.uminho.pt.

\section{Notes}

620 The authors declare no competing financial interest.

\section{ACKNOWLEDGMENTS}

622 This work was supported by the ARTICULATE project 623 (QREN-13/SI/2011-23189).

\section{$624 \square$ REFERENCES}

625 (1) Buckwalter, J. A. Articular cartilage: injuries and potential for 626 healing. J. Orthop Sports Phys. Ther 1998, 28 (4), 192-202.

627 (2) Hunziker, E. B. Articular cartilage repair: are the intrinsic 628 biological constraints undermining this process insuperable? Osteo629 arthritis Cartilage 1999, 7 (1), 15-28.

630 (3) Hjelle, K.; Solheim, E.; Strand, T.; Muri, R.; Brittberg, M. 631 Articular cartilage defects in 1,000 knee arthroscopies. Arthroscopy 632 2002, 18 (7), 730-4.

633 (4) Hunziker, E. B. Articular cartilage repair: basic science and clinical 634 progress. A review of the current status and prospects. Osteoarthritis 635 Cartilage 2002, 10 (6), 432-63.

636 (5) Tanna, S. Background Paper 6.12 Osteoarthritis. In Priority 637 Medicines for Europe and the World "A Public Health Approach to 638 Innovation", Wittenauer, R., Smith, L., Aden, K., Eds.; World Health 639 Organization: Geneva, Switzerland, 2013.

640 (6) Jackson, D. W.; Simon, T. M.; Aberman, H. M. Symptomatic 641 articular cartilage degeneration: the impact in the new millennium. 642 Clin. Orthop. Relat. Res. 2001, 391 Suppl, S14-25.

643 (7) Tins, B. J.; McCall, I. W.; Takahashi, T.; Cassar-Pullicino, V.; 644 Roberts, S.; Ashton, B.; Richardson, J. Autologous chondrocyte 645 implantation in knee joint: MR imaging and histologic features at 1646 year follow-up. Radiology 2005, 234 (2), 501-8.
(8) Gobbi, A.; Nunag, P.; Malinowski, K. Treatment of full thickness 647 chondral lesions of the knee with microfracture in a group of athletes. 648 Knee Surg Sports Traumatol Arthrosc 2005, 13 (3), 213-21. 649

(9) Luyten, F. P.; Vanlauwe, J. Tissue engineering approaches for 650 osteoarthritis. Bone 2012, 51 (2), 289-96.

651

(10) Brittberg, M.; Lindahl, A.; Nilsson, A.; Ohlsson, C.; Isaksson, 652 O.; Peterson, L. Treatment of deep cartilage defects in the knee with 653 autologous chondrocyte transplantation. N. Engl. J. Med. 1994, 331654 (14), 889-95.

(11) Cabral, J.; Moratti, S. C. Hydrogels for biomedical applications. 656 Future Med. Chem. 2011, 3 (15), 1877-88. 657

(12) Baroli, B. Hydrogels for tissue engineering and delivery of 658 tissue-inducing substances. J. Pharm. Sci. 2007, 96 (9), 2197-223. 659 (13) Gauvin, R.; Parenteau-Bareil, R.; Dokmeci, M. R.; Merryman, 660 W. D.; Khademhosseini, A. Hydrogels and microtechnologies for 661 engineering the cellular microenvironment. Wiley Interdiscip Rev. 662 Nanomed Nanobiotechnol 2012, 4 (3), 235-46.

(14) Oliveira, J. T.; Reis, R. L. Polysaccharide-based materials for 664 cartilage tissue engineering applications. J. Tissue Eng. Regener. Med. 665 2011, 5 (6), 421-36.

(15) Khademhosseini, A.; Langer, R.; Borenstein, J.; Vacanti, J. P. 667 Microscale technologies for tissue engineering and biology. Proc. Natl. 668 Acad. Sci. U. S. A. 2006, 103 (8), 2480-7.

(16) Khademhosseini, A.; Langer, R. Microengineered hydrogels for 670 tissue engineering. Biomaterials 2007, 28 (34), 5087-92. 671

(17) Filova, E.; Jelinek, F.; Handl, M.; Lytvynets, A.; Rampichova, 672 M.; Varga, F.; Cinatl, J.; Soukup, T.; Trc, T.; Amler, E. Novel 673 composite hyaluronan/type I collagen/fibrin scaffold enhances repair 674 of osteochondral defect in rabbit knee. J. Biomed. Mater. Res., Part B 675 2008, 87 (2), 415-424.

(18) Pei, M.; He, F.; Boyce, B. M.; Kish, V. L. Repair of full-thickness 677 femoral condyle cartilage defects using allogeneic synovial cell- 678 engineered tissue constructs. Osteoarthritis Cartilage 2009, 17 (6), 679 714-22.

(19) Siu, R. K.; Zara, J. N.; Hou, Y.; James, A. W.; Kwak, J.; Zhang, 681 X.; Ting, K.; Wu, B. M.; Soo, C.; Lee, M. NELL-1 promotes cartilage 682 regeneration in an in vivo rabbit model. Tissue Eng., Part A 2012, 18683 (3-4), 252-261.

(20) Wang, W.; Li, B.; Yang, J.; Xin, L.; Li, Y.; Yin, H.; Qi, Y.; Jiang, 685 Y.; Ouyang, H.; Gao, C. The restoration of full-thickness cartilage 686 defects with BMSCs and TGF-beta 1 loaded PLGA/fibrin gel 687 constructs. Biomaterials 2010, 31 (34), 8964-73. 688

(21) Adachi, N.; Sato, K.; Usas, A.; Fu, F. H.; Ochi, M.; Han, C. W.; 689 Niyibizi, C.; Huard, J. Muscle derived, cell based ex vivo gene therapy 690 for treatment of full thickness articular cartilage defects. J. Rheumatol. 691 2002, 29 (9), 1920-1930.

692

(22) Han, C. W.; Chu, C. R.; Adachi, N.; Usas, A.; Fu, F. H.; Huard, 693 J.; Pan, Y. Analysis of rabbit articular cartilage repair after chondrocyte 694 implantation using optical coherence tomography. Osteoarthritis 695 Cartilage 2003, 11 (2), 111-21.

(23) Cohen, S. B.; Meirisch, C. M.; Wilson, H. A.; Diduch, D. R. The 697 use of absorbable co-polymer pads with alginate and cells for articular 698 cartilage repair in rabbits. Biomaterials 2003, 24 (15), 2653-2660. 699

(24) Fukuda, A.; Kato, K.; Hasegawa, M.; Hirata, H.; Sudo, A.; 700 Okazaki, K.; Tsuta, K.; Shikinami, Y.; Uchida, A. Enhanced repair of 701 large osteochondral defects using a combination of artificial cartilage 702 and basic fibroblast growth factor. Biomaterials 2005, 26 (20), 4301-8. 703 (25) Yanai, T.; Ishii, T.; Chang, F.; Ochiai, N. Repair of large full- 704 thickness articular cartilage defects in the rabbit: the effects of joint 705 distraction and autologous bone-marrow-derived mesenchymal cell 706 transplantation. J. Bone Jt. Surg., Br. Vol. 2005, 87 (5), 721-9. 707

(26) Lee, J. H.; Prakash, K. V.; Pengatteeri, Y. H.; Park, S. E.; Koh, H. 708 S.; Han, C. W. Chondrocyte apoptosis in the regenerated articular 709 cartilage after allogenic chondrocyte transplantation in the rabbit knee. 710 J. Bone Jt. Surg., Br. Vol. 2007, 89 (7), 977-983. 711

(27) Kang, S. W.; Bada, L. P.; Kang, C. S.; Lee, J. S.; Kim, C. H.; 712 Park, J. H.; Kim, B. S. Articular cartilage regeneration with 713 microfracture and hyaluronic acid. Biotechnol. Lett. 2008, 30 (3), 714 435-9. 
716 (28) Koga, H.; Muneta, T.; Nagase, T.; Nimura, A.; Ju, Y. J.; 717 Mochizuki, T.; Sekiya, I. Comparison of mesenchymal tissues-derived 718 stem cells for in vivo chondrogenesis: suitable conditions for cell 719 therapy of cartilage defects in rabbit. Cell Tissue Res. 2008, 333 (2), 720 207-15.

721 (29) Chang, F.; Ishii, T.; Yanai, T.; Mishima, H.; Akaogi, H.; Ogawa, 722 T.; Ochiai, N. Repair of large full-thickness articular cartilage defects 723 by transplantation of autologous uncultured bone-marrow-derived 724 mononuclear cells. J. Orthop. Res. 2008, 26 (1), 18-26.

725 (30) Aulin, C.; Bergman, K.; Jensen-Waern, M.; Hedenqvist, P.; 726 Hilborn, J.; Engstrand, T. In situ cross-linkable hyaluronan hydrogel 727 enhances chondrogenesis. J. Tissue Eng. Regener. Med. 2011, 5 (8), 728 e188-96.

729 (31) Aulin, C.; Jensen-Waern, M.; Ekman, S.; Hagglund, M.; 730 Engstrand, T.; Hilborn, J.; Hedenqvist, P. Cartilage repair of 731 experimentally 11 induced osteochondral defects in New Zealand 732 White rabbits. Lab. Anim. 2013, 47 (1), 58-65.

733 (32) Pulkkinen, H. J.; Tiitu, V.; Valonen, P.; Jurvelin, J. S.; Rieppo, L.; 734 Toyras, J.; Silvast, T. S.; Lammi, M. J.; Kiviranta, I. Repair of 735 osteochondral defects with recombinant human type II collagen gel 736 and autologous chondrocytes in rabbit. Osteoarthritis Cartilage 2013, 73721 (3), 481-90.

738 (33) Wilke, M. M.; Nydam, D. V.; Nixon, A. J. Enhanced early 739 chondrogenesis in articular defects following arthroscopic mesen740 chymal stem cell implantation in an equine model. J. Orthop. Res. 741 2007, 25 (7), 913-25.

742 (34) Marquass, B.; Somerson, J. S.; Hepp, P.; Aigner, T.; Schwan, S.; 743 Bader, A.; Josten, C.; Zscharnack, M.; Schulz, R. M. A novel MSC744 seeded triphasic construct for the repair of osteochondral defects. J. 745 Orthop. Res. 2010, 28 (12), 1586-99.

746 (35) Shah, R. N.; Shah, N. A.; Del Rosario Lim, M. M.; Hsieh, C.; 747 Nuber, G.; Stupp, S. I. Supramolecular design of self-assembling 748 nanofibers for cartilage regeneration. Proc. Natl. Acad. Sci. U. S. A. 749 2010, 107 (8), 3293-8.

750 (36) Portron, S.; Merceron, C.; Gauthier, O.; Lesoeur, J.; Sourice, S.; 751 Masson, M.; Fellah, B. H.; Geffroy, O.; Lallemand, E.; Weiss, P.; 752 Guicheux, J.; Vinatier, C. Effects of in vitro low oxygen tension 753 preconditioning of adipose stromal cells on their in vivo chondrogenic 754 potential: application in cartilage tissue repair. PLoS One 2013, 8 (4), 755 e62368.

756 (37) Madry, H.; Cucchiarini, M.; Stein, U.; Remberger, K.; Menger, 757 M. D.; Kohn, D.; Trippel, S. B. Sustained transgene expression in 758 cartilage defects in vivo after transplantation of articular chondrocytes 759 modified by lipid-mediated gene transfer in a gel suspension delivery 760 system. J. Gene Med. 2003, 5 (6), 502-9.

761 (38) Mierisch, C. M.; Wilson, H. A.; Turner, M. A.; Milbrandt, T. A.; 762 Berthoux, L.; Hammarskjold, M. L.; Rekosh, D.; Balian, G.; Diduch, D. 763 R. Chondrocyte transplantation into articular cartilage defects with use 764 of calcium alginate: the fate of the cells. J. Bone Jt. Surg. Am. 2003, 85 765 (9), 1757-1767.

766 (39) Chang, C. H.; Kuo, T. F.; Lin, F. H.; Wang, J. H.; Hsu, Y. M.; 767 Huang, H. T.; Loo, S. T.; Fang, H. W.; Liu, H. C.; Wang, W. C. Tissue 768 engineering-based cartilage repair with mesenchymal stem cells in a 769 porcine model. J. Orthop. Res. 2011, 29 (12), 1874-80.

770 (40) Heiligenstein, S.; Cucchiarini, M.; Laschke, M. W.; Bohle, R. M.; 771 Kohn, D.; Menger, M. D.; Madry, H. In vitro and in vivo 772 characterization of nonbiomedical- and biomedical-grade alginates 773 for articular chondrocyte transplantation. Tissue Eng., Part C 2011, 17 774 (8), 829-42.

775 (41) Filova, E.; Rampichova, M.; Litvinec, A.; Drzik, M.; Mickova, A.; 776 Buzgo, M.; Kostakova, E.; Martinova, L.; Usvald, D.; Prosecka, E.; 777 Uhlik, J.; Motlik, J.; Vajner, L.; Amler, E. A cell-free nanofiber 778 composite scaffold regenerated osteochondral defects in miniature 779 pigs. Int. J. Pharm. 2013, 447 (1-2), 139-49.

780 (42) Martins, E. A.; Michelacci, Y. M.; Baccarin, R. Y.; Cogliati, B.; 781 Silva, L. C. Evaluation of chitosan-GP hydrogel biocompatibility in 782 osteochondral defects: an experimental approach. BMC Vet. Res. 2014, $78310(1), 197$.
(43) Hui, J. H.; Ren, X.; Afizah, M. H.; Chian, K. S.; Mikos, A. G. 784 Oligo[poly(ethylene glycol)fumarate] hydrogel enhances osteochon- 785 dral repair in porcine femoral condyle defects. Clin. Orthop. Relat. Res. 786 2013, 471 (4), 1174-85.

(44) Guo, X.; Park, H.; Young, S.; Kretlow, J. D.; van den Beucken, J. 788 J.; Baggett, L. S.; Tabata, Y.; Kasper, F. K.; Mikos, A. G.; Jansen, J. A. 789 Repair of osteochondral defects with biodegradable hydrogel 790 composites encapsulating marrow mesenchymal stem cells in a rabbit 791 model. Acta Biomater. 2010, 6 (1), 39-47.

(45) Ferretti, M.; Marra, K. G.; Kobayashi, K.; Defail, A. J.; Chu, C. 793 $\mathrm{R}$. Controlled in vivo degradation of genipin crosslinked polyethylene 794 glycol hydrogels within osteochondral defects. Tissue Eng. 2006, 12795 (9), 2657-63.

(46) Holland, T. A.; Bodde, E. W.; Cuijpers, V. M.; Baggett, L. S.; 797 Tabata, Y.; Mikos, A. G.; Jansen, J. A. Degradable hydrogel scaffolds 798 for in vivo delivery of single and dual growth factors in cartilage repair. 799 Osteoarthritis Cartilage 2007, 15 (2), 187-97.

800

(47) Mimura, T.; Imai, S.; Kubo, M.; Isoya, E.; Ando, K.; Okumura, 801 N.; Matsusue, Y. A novel exogenous concentration-gradient collagen 802 scaffold augments full-thickness articular cartilage repair. Osteoarthritis 803 Cartilage 2008, 16 (9), 1083-91.

804

(48) Sun, J.; Hou, X. K.; Li, X.; Tang, T. T.; Zhang, R. M.; Kuang, Y.; 805 Shi, M. Mosaicplasty associated with gene enhanced tissue engineering 806 for the treatment of acute osteochondral defects in a goat model. Arch 807 Orthop Trauma Surg 2009, 129 (6), 757-71.

(49) Rampichova, M.; Filova, E.; Varga, F.; Lytvynets, A.; Prosecka, 809 E.; Kolacna, L.; Motlik, J.; Necas, A.; Vajner, L.; Uhlik, J.; Amler, E. 810 Fibrin/hyaluronic acid composite hydrogels as appropriate scaffolds 811 for in vivo artificial cartilage implantation. ASAIO J. 2010, 56 (6), 812 $563-8$.

(50) Yamazoe, K.; Mishima, H.; Torigoe, K.; Iijima, H.; Watanabe, 814 K.; Sakai, H.; Kudo, T. Effects of atelocollagen gel containing bone 815 marrow-derived stromal cells on repair of osteochondral defect in a 816 dog. J. Vet. Med. Sci. 2007, 69 (8), 835-9.

817

(51) Zheng, Y.; Lv, H.; Wang, Y.; Lu, H.; Qing, L.; Xi, T. 818 Performance of novel bioactive hybrid hydrogels in vitro and in vivo 819 used for artificial cartilage. Biomed. Mater. 2009, 4 (1), 015015. 820

(52) Tanaka, H.; Mizokami, H.; Shiigi, E.; Murata, H.; Ogasa, H.; 821 Mine, T.; Kawai, S. Effects of basic fibroblast growth factor on the 822 repair of large osteochondral defects of articular cartilage in rabbits: 823 dose-response effects and long-term outcomes. Tissue Eng. 2004, 10824 (3-4), 633-41.

(53) Tanaka, T.; Komaki, H.; Chazono, M.; Fujii, K. Use of a 826 biphasic graft constructed with chondrocytes overlying a beta- 827 tricalcium phosphate block in the treatment of rabbit osteochondral 828 defects. Tissue Eng. 2005, 11 (1-2), 331-9.

829

(54) Shao, X. X.; Hutmacher, D. W.; Ho, S. T.; Goh, J. C.; Lee, E. H. 830 Evaluation of a hybrid scaffold/cell construct in repair of high-load- 831 bearing osteochondral defects in rabbits. Biomaterials 2006, 27 (7), 832 1071-80.

(55) Kim, K.; Lam, J.; Lu, S.; Spicer, P. P.; Lueckgen, A.; Tabata, Y.; 834 Wong, M. E.; Jansen, J. A.; Mikos, A. G.; Kasper, F. K. Osteochondral 835 tissue regeneration using a bilayered composite hydrogel with 836 modulating dual growth factor release kinetics in a rabbit model. J. 837 Controlled Release 2013, 168 (2), 166-78.

838

(56) Qi, B. W.; Yu, A. X.; Zhu, S. B.; Zhou, M.; Wu, G. Chitosan/ 839 poly(vinyl alcohol) hydrogel combined with Ad-hTGF-betal trans- 840 fected mesenchymal stem cells to repair rabbit articular cartilage 841 defects. Exp. Biol. Med. (London, U. K.) 2013, 238 (1), 23. (57) Lee, K. B.; Hui, J. H.; Song, I. C.; Ardany, L.; Lee, E. H. 843 Injectable mesenchymal stem cell therapy for large cartilage defects-a 844 porcine model. Stem Cells 2007, 25 (11), 2964-71.

(58) Zhang, Y.; Wang, F.; Chen, J.; Ning, Z.; Yang, L. Bone marrow- 846 derived mesenchymal stem cells versus bone marrow nucleated cells in 847 the treatment of chondral defects. Int. Orthop. 2012, 36 (5), 1079-86. 848 (59) Wang, W.; Li, B.; Li, Y.; Jiang, Y.; Ouyang, H.; Gao, C. In vivo 849 restoration of full-thickness cartilage defects by poly(lactide-co- 850 glycolide) sponges filled with fibrin gel, bone marrow mesenchymal 851 stem cells and DNA complexes. Biomaterials 2010, 31 (23), 5953-65. 852 
853 (60) Filova, E.; Rampichova, M.; Handl, M.; Lytvynets, A.; Halouzka, 854 R.; Usvald, D.; Hlucilova, J.; Prochazka, R.; Dezortova, M.; Rolencova, 855 E.; Kostakova, E.; Trc, T.; Stastny, E.; Kolacna, L.; Hajek, M.; Motlik, 856 J.; Amler, E. Composite hyaluronate-type I collagen-fibrin scaffold in 857 the therapy of osteochondral defects in miniature pigs. Physiol. Res. 858 2007, 56 (Suppl 1), S5-S16.

859 (61) Kuo, T. F.; Lin, M. F.; Lin, Y. H.; Lin, Y. C.; Su, R. J.; Lin, H. 860 W.; Chan, W. P. Implantation of platelet-rich fibrin and cartilage 861 granules facilitates cartilage repair in the injured rabbit knee: 862 preliminary report. Clinics (Sao Paulo) 2011, 66 (10), 1835-8.

863 (62) Mierisch, C. M.; Cohen, S. B.; Jordan, L. C.; Robertson, P. G.; 864 Balian, G.; Diduch, D. R. Transforming growth factor-beta in calcium 865 alginate beads for the treatment of articular cartilage defects in the 866 rabbit. Arthroscopy 2002, 18 (8), 892-900.

867 (63) Zscharnack, M.; Hepp, P.; Richter, R.; Aigner, T.; Schulz, R.; 868 Somerson, J.; Josten, C.; Bader, A.; Marquass, B. Repair of chronic 869 osteochondral defects using predifferentiated mesenchymal stem cells 870 in an ovine model. Am. J. Sports Med. 2010, 38 (9), 1857-69.

871 (64) Marquass, B.; Schulz, R.; Hepp, P.; Zscharnack, M.; Aigner, T.; 872 Schmidt, S.; Stein, F.; Richter, R.; Osterhoff, G.; Aust, G.; Josten, C.; 873 Bader, A. Matrix-associated implantation of predifferentiated mesen874 chymal stem cells versus articular chondrocytes: in vivo results of 875 cartilage repair after 1 year. Am. J. Sports Med. 2011, 39 (7), 1401-12. 876 (65) Miller, R. E.; Grodzinsky, A. J.; Vanderploeg, E. J.; Lee, C.; 877 Ferris, D. J.; Barrett, M. F.; Kisiday, J. D.; Frisbie, D. D. Effect of self878 assembling peptide, chondrogenic factors, and bone marrow-derived 879 stromal cells on osteochondral repair. Osteoarthritis Cartilage 2010, 18 880 (12), 1608-19.

881 (66) Chiang, H.; Kuo, T. F.; Tsai, C. C.; Lin, M. C.; She, B. R.; 882 Huang, Y. Y.; Lee, H. S.; Shieh, C. S.; Chen, M. H.; Ramshaw, J. A.; 883 Werkmeister, J. A.; Tuan, R. S.; Jiang, C. C. Repair of porcine articular 884 cartilage defect with autologous chondrocyte transplantation. J. Orthop. 885 Res. 2005, 23 (3), 584-93.

886 (67) Schagemann, J. C.; Erggelet, C.; Chung, H. W.; Lahm, A.; Kurz, 887 H.; Mrosek, E. H. Cell-laden and cell-free biopolymer hydrogel for the 888 treatment of osteochondral defects in a sheep model. Tissue Eng., Part 889 A 2009, 15 (1), 75-82.

890 (68) Liu, Y.; Shu, X. Z.; Prestwich, G. D. Osteochondral defect repair 891 with autologous bone marrow-derived mesenchymal stem cells in an 892 injectable, in situ, cross-linked synthetic extracellular matrix. Tissue 893 Eng. 2006, 12 (12), 3405-16.

894 (69) Duarte Campos, D. F.; Drescher, W.; Rath, B.; Tingart, M.; 895 Fischer, H. Supporting Biomaterials for Articular Cartilage Repair. 896 Cartilage 2012, 3 (3), 205-21.

897 (70) Cao, Z.; Dou, C.; Dong, S. Scaffolding Biomaterials for Cartilage 898 Regeneration. J. Nanomater. 2014, 2014, 1-8.

899 (71) Katayama, R.; Wakitani, S.; Tsumaki, N.; Morita, Y.; Matsushita, 900 I.; Gejo, R.; Kimura, T. Repair of articular cartilage defects in rabbits 901 using CDMP1 gene-transfected autologous mesenchymal cells derived 902 from bone marrow. Rheumatology (Oxford) 2004, 43 (8), 980-5.

903 (72) Yokoo, N.; Saito, T.; Uesugi, M.; Kobayashi, N.; Xin, K. Q.; 904 Okuda, K.; Mizukami, H.; Ozawa, K.; Koshino, T. Repair of articular 905 cartilage defect by autologous transplantation of basic fibroblast 906 growth factor gene-transduced chondrocytes with adeno-associated 907 virus vector. Arthritis Rheum. 2005, 52 (1), 164-70.

908 (73) Kubo, M.; Imai, S.; Fujimiya, M.; Isoya, E.; Ando, K.; Mimura, 909 T.; Matsusue, Y. Exogenous collagen-enhanced recruitment of 910 mesenchymal stem cells during rabbit articular cartilage repair. Acta 911 Orthop. 2007, 78 (6), 845-55.

912 (74) Mimura, T.; Imai, S.; Okumura, N.; Li, L.; Nishizawa, K.; Araki, 913 S.; Ueba, H.; Kubo, M.; Mori, K.; Matsusue, Y. Spatiotemporal control 914 of proliferation and differentiation of bone marrow-derived mesen915 chymal stem cells recruited using collagen hydrogel for repair of 916 articular cartilage defects. J. Biomed. Mater. Res., Part B 2011, 98 (2), 917 360-8.

918 (75) Schneider, U.; Schmidt-Rohlfing, B.; Gavenis, K.; Maus, U.; 919 Mueller-Rath, R.; Andereya, S. A comparative study of 3 different 920 cartilage repair techniques. Knee Surg Sports Traumatol Arthrosc 2011, 92119 (12), 2145-52.
(76) Chen, J.; Wang, F.; Zhang, Y.; Jin, X.; Zhang, L.; Feng, Y.; Lin, 922 $\mathrm{X}$.; Yang, L. In vivo tracking of superparamagnetic iron oxide 923 nanoparticle labeled chondrocytes in large animal model. Ann. Biomed. 924 Eng. 2012, 40 (12), 2568-78.

(77) Igarashi, T.; Iwasaki, N.; Kasahara, Y.; Minami, A. A cellular 926 implantation system using an injectable ultra-purified alginate gel for 927 repair of osteochondral defects in a rabbit model. J. Biomed. Mater. Res., 928 Part A 2010, 94 (3), 844-855.

929

(78) Re'em, T.; Witte, F.; Willbold, E.; Ruvinov, E.; Cohen, S. 930 Simultaneous regeneration of articular cartilage and subchondral bone 931 induced by spatially presented TGF-beta and BMP-4 in a bilayer 932 affinity binding system. Acta Biomater. 2012, 8 (9), 3283-93.

(79) Lopiz-Morales, Y.; Abarrategi, A.; Ramos, V.; Moreno-Vicente, 934 C.; Lopez-Duran, L.; Lopez-Lacomba, J. L.; Marco, F. In vivo 935 comparison of the effects of rhBMP-2 and rhBMP-4 in osteochondral 936 tissue regeneration. Eur. Cell Mater. 2010, 20, 367-78.

937

(80) Araki, S.; Imai, S.; Ishigaki, H.; Mimura, T.; Nishizawa, K.; Ueba, 938 H.; Kumagai, K.; Kubo, M.; Mori, K.; Ogasawara, K.; Matsusue, Y. 939 Improved quality of cartilage repair by bone marrow mesenchymal 940 stem cells for treatment of an osteochondral defect in a cynomolgus 941 macaque model. Acta Orthop 2015, 86 (1), 119-26.

942

(81) Dragoo, J. L.; Carlson, G.; McCormick, F.; Khan-Farooqi, H.; 943 Zhu, M.; Zuk, P. A.; Benhaim, P. Healing full-thickness cartilage 944 defects using adipose-derived stem cells. Tissue Eng. 2007, 13 (7), 945 1615-21.

946

(82) Lee, J. M.; Im, G. I. SOX trio-co-transduced adipose stem cells 947 in fibrin gel to enhance cartilage repair and delay the progression of 948 osteoarthritis in the rat. Biomaterials 2012, 33 (7), 2016-24. 949

(83) Lee, J. C.; Min, H. J.; Park, H. J.; Lee, S.; Seong, S. C.; Lee, M. 950 C. Synovial membrane-derived mesenchymal stem cells supported by 951 platelet-rich plasma can repair osteochondral defects in a rabbit model. 952 Arthroscopy 2013, 29 (6), 1034-46.

953

(84) Kayakabe, M.; Tsutsumi, S.; Watanabe, H.; Kato, Y.; Takagishi, 954 K. Transplantation of autologous rabbit BM-derived mesenchymal 955 stromal cells embedded in hyaluronic acid gel sponge into 956 osteochondral defects of the knee. Cytotherapy 2006, 8 (4), 343-53. 957

(85) Fisher, M. B.; Belkin, N. S.; Milby, A. H.; Henning, E. A.; 958 Bostrom, M.; Kim, M.; Pfeifer, C.; Meloni, G.; Dodge, G. R.; Burdick, 959 J. A.; Schaer, T. P.; Steinberg, D. R.; Mauck, R. L. Cartilage repair and 960 subchondral bone remodeling in response to focal lesions in a mini-pig 961 model: implications for tissue engineering. Tissue Eng., Part A 2015, 21962 (3-4), 850-860.

(86) Oliveira, J. T.; Gardel, L. S.; Rada, T.; Martins, L.; Gomes, M. 964 E.; Reis, R. L. Injectable gellan gum hydrogels with autologous cells for 965 the treatment of rabbit articular cartilage defects. J. Orthop. Res. 2010, 966 28 (9), 1193-9.

(87) Hao, T.; Wen, N.; Cao, J. K.; Wang, H. B.; Lu, S. H.; Liu, T.; 968 Lin, Q. X.; Duan, C. M.; Wang, C. Y. The support of matrix 969 accumulation and the promotion of sheep articular cartilage defects 970 repair in vivo by chitosan hydrogels. Osteoarthritis Cartilage 2010, 18971 (2), 257-65.

(88) Albuquerque, P. C.; Aguiar, J. L.; Santos, S. M.; Pontes Filho, 973 N.; Mello, R. J.; Costa, M. L.; Albuquerque, C. M.; Almeida, T. M.; 974 Santos, A. H.; Silva, J. C. Comparative study of the areas of 975 osteochondral defects produced in the femoral condyles of rabbits 976 treated with gel of sugarcane biopolymer. Acta Cir Bras 2011, 26 (5), 977 383-6.

(89) Lim, C. T.; Ren, X.; Afizah, M. H.; Tarigan-Panjaitan, S.; Yang, 979 Z.; Wu, Y.; Chian, K. S.; Mikos, A. G.; Hui, J. H. Repair of 980 osteochondral defects with rehydrated freeze-dried oligo[poly-981 (ethylene glycol) fumarate] hydrogels seeded with bone marrow 982 mesenchymal stem cells in a porcine model. Tissue Eng., Part A 2013, 983 19 (15-16), 1852-1861.

(90) Park, J. S.; Woo, D. G.; Yang, H. N.; Lim, H. J.; Park, K. M.; Na, 985 K.; Park, K. H. Chondrogenesis of human mesenchymal stem cells 986 encapsulated in a hydrogel construct: neocartilage formation in animal 987 models as both mice and rabbits. J. Biomed. Mater. Res., Part A 2010, 988 92 (3), 988-996. 
990 (91) Jung, Y.; Park, M. S.; Lee, J. W.; Kim, Y. H.; Kim, S. H. Cartilage 991 regeneration with highly-elastic three-dimensional scaffolds prepared 992 from biodegradable poly(L-lactide-co-epsilon-caprolactone). Biomate993 rials 2008, 29 (35), 4630-4636.

994 (92) Dahlin, R. L.; Kinard, L. A.; Lam, J.; Needham, C. J.; Lu, S.; 995 Kasper, F. K.; Mikos, A. G. Articular chondrocytes and mesenchymal 996 stem cells seeded on biodegradable scaffolds for the repair of cartilage 997 in a rat osteochondral defect model. Biomaterials 2014, 35 (26), 998 7460-9.

999 (93) Nettles, D. L.; Kitaoka, K.; Hanson, N. A.; Flahiff, C. M.; Mata, 1000 B. A.; Hsu, E. W.; Chilkoti, A.; Setton, L. A. In situ crosslinking elastin1001 like polypeptide gels for application to articular cartilage repair in a 1002 goat osteochondral defect model. Tissue Eng., Part A 2008, 14 (7), 1003 1133-1140.

1004 (94) Hui, J. H.; Chan, S. W.; Li, J.; Goh, J. C.; Li, L.; Ren, X. F.; Lee, 1005 E. H. Intra-articular delivery of chondroitin sulfate for the treatment of 1006 joint defects in rabbit model. J. Mol. Histol. 2007, 38 (5), 483-9.

1007 (95) Dausse, Y.; Grossin, L.; Miralles, G.; Pelletier, S.; Mainard, D.; 1008 Hubert, P.; Baptiste, D.; Gillet, P.; Dellacherie, E.; Netter, P.; Payan, E. 1009 Cartilage repair using new polysaccharidic biomaterials: macroscopic, 1010 histological and biochemical approaches in a rat model of cartilage 1011 defect. Osteoarthritis Cartilage 2003, 11 (1), 16-28.

1012 (96) Nishida, T.; Kubota, S.; Kojima, S.; Kuboki, T.; Nakao, K.; 1013 Kushibiki, T.; Tabata, Y.; Takigawa, M. Regeneration of defects in 1014 articular cartilage in rat knee joints by CCN2 (connective tissue 1015 growth factor). J. Bone Miner. Res. 2004, 19 (8), 1308-19.

1016 (97) Ishii, I.; Mizuta, H.; Sei, A.; Hirose, J.; Kudo, S.; Hiraki, Y. 1017 Healing of full-thickness defects of the articular cartilage in rabbits 1018 using fibroblast growth factor-2 and a fibrin sealant. J. Bone Jt. Surg., Br. 1019 Vol. 2007, 89 (5), 693-700.

1020 (98) Park, S. H.; Cui, J. H.; Park, S. R.; Min, B. H. Potential of 1021 fortified fibrin/hyaluronic acid composite gel as a cell delivery vehicle 1022 for chondrocytes. Artif. Organs 2009, 33 (6), 439-47.

1023 (99) Lee, J. C.; Lee, S. Y.; Min, H. J.; Han, S. A.; Jang, J.; Lee, S.; 1024 Seong, S. C.; Lee, M. C. Synovium-derived mesenchymal stem cells 1025 encapsulated in a novel injectable gel can repair osteochondral defects 1026 in a rabbit model. Tissue Eng., Part A 2012, 18 (19-20), 2173-2186. 1027 (100) Park, J. S.; Yang, H. N.; Woo, D. G.; Jeon, S. Y.; Park, K. H. 1028 Chondrogenesis of human mesenchymal stem cells in fibrin constructs 1029 evaluated in vitro and in nude mouse and rabbit defects models. 1030 Biomaterials 2011, 32 (6), 1495-507.

1031 (101) Yasuda, K.; Kitamura, N.; Gong, J. P.; Arakaki, K.; Kwon, H. J.; 1032 Onodera, S.; Chen, Y. M.; Kurokawa, T.; Kanaya, F.; Ohmiya, Y.; 1033 Osada, Y. A novel double-network hydrogel induces spontaneous 1034 articular cartilage regeneration in vivo in a large osteochondral defect. 1035 Macromol. Biosci. 2009, 9 (4), 307-16.

1036 (102) Imabuchi, R.; Ohmiya, Y.; Kwon, H. J.; Onodera, S.; Kitamura, 1037 N.; Kurokawa, T.; Gong, J. P.; Yasuda, K. Gene expression profile of 1038 the cartilage tissue spontaneously regenerated in vivo by using a novel 1039 double-network gel: comparisons with the normal articular cartilage. 1040 BMC Musculoskeletal Disord. 2011, 12, 213.

1041 (103) Yokota, M.; Yasuda, K.; Kitamura, N.; Arakaki, K.; Onodera, S.; 1042 Kurokawa, T.; Gong, J. P. Spontaneous hyaline cartilage regeneration 1043 can be induced in an osteochondral defect created in the femoral 1044 condyle using a novel double-network hydrogel. BMC Musculoskeletal 1045 Disord. 2011, 12, 49.

1046 (104) Kitamura, N.; Yasuda, K.; Ogawa, M.; Arakaki, K.; Kai, S.; 1047 Onodera, S.; Kurokawa, T.; Gong, J. P. Induction of spontaneous 1048 hyaline cartilage regeneration using a double-network gel: efficacy of a 1049 novel therapeutic strategy for an articular cartilage defect. Am. J. Sports 1050 Med. 2011, 39 (6), 1160-9.

1051 (105) Ogawa, M.; Kitamura, N.; Kurokawa, T.; Arakaki, K.; Tanaka, 1052 Y.; Gong, J. P.; Yasuda, K. Poly(2-acrylamido-2-methylpropanesulfonic 1053 acid) gel induces articular cartilage regeneration in vivo: comparisons 1054 of the induction ability between single- and double-network gels. J. 1055 Biomed. Mater. Res., Part A 2012, 100 (9), 2244-2251.

1056 (106) Matsuda, H.; Kitamura, N.; Kurokawa, T.; Arakaki, K.; Gong, J. 1057 P.; Kanaya, F.; Yasuda, K. Influence of the gel thickness on in vivo 1058 hyaline cartilage regeneration induced by double-network gel implanted at the bottom of a large osteochondral defect: short-term 1059 results. BMC Musculoskeletal Disord. 2013, 14, 50.

1060

(107) Degoricija, L.; Bansal, P. N.; Sontjens, S. H.; Joshi, N. S.; 1061 Takahashi, M.; Snyder, B.; Grinstaff, M. W. Hydrogels for 1062 osteochondral repair based on photocrosslinkable carbamate den- 1063 drimers. Biomacromolecules 2008, 9 (10), 2863-72.

1064

(108) Shokrgozar, M. A.; Bonakdar, S.; Dehghan, M. M.; Emami, S. 1065 H.; Montazeri, L.; Azari, S.; Rabbani, M. Biological evaluation of 1066 polyvinyl alcohol hydrogel crosslinked by polyurethane chain for 1067 cartilage tissue engineering in rabbit model. J. Mater. Sci.: Mater. Med. 1068 2013, 24 (10), 2449-2460.

1069

(109) Fukui, T.; Kitamura, N.; Kurokawa, T.; Yokota, M.; Kondo, E.; 1070 Gong, J. P.; Yasuda, K. Intra-articular administration of hyaluronic acid 1071 increases the volume of the hyaline cartilage regenerated in a large 1072 osteochondral defect by implantation of a double-network gel. J. Mater. 1073 Sci.: Mater. Med. 2014, 25 (4), 1173-82. 1074 (110) Holland, T. A.; Bodde, E. W.; Baggett, L. S.; Tabata, Y.; Mikos, 1075 A. G.; Jansen, J. A. Osteochondral repair in the rabbit model utilizing 1076 bilayered, degradable oligo(poly(ethylene glycol) fumarate) hydrogel 1077 scaffolds. J. Biomed. Mater. Res., Part A 2005, 75 (1), 156-167. 1078

(111) Ito, Y.; Ochi, M.; Adachi, N.; Sugawara, K.; Yanada, S.; Ikada, 1079 Y.; Ronakorn, P. Repair of osteochondral defect with tissue-engineered 1080 chondral plug in a rabbit model. Arthroscopy 2005, 21 (10), 1155-63. 1081 (112) Funayama, A.; Niki, Y.; Matsumoto, H.; Maeno, S.; Yatabe, T.; 1082 Morioka, H.; Yanagimoto, S.; Taguchi, T.; Tanaka, J.; Toyama, Y. 1083 Repair of full-thickness articular cartilage defects using injectable type 1084 II collagen gel embedded with cultured chondrocytes in a rabbit 1085 model. J. Orthop. Sci. 2008, 13 (3), 225-32.

1086

(113) Lind, M.; Larsen, A.; Clausen, C.; Osther, K.; Everland, H. 1087 Cartilage repair with chondrocytes in fibrin hydrogel and MPEG 1088 polylactide scaffold: an in vivo study in goats. Knee Surg Sports 1089 Traumatol Arthrosc 2008, 16 (7), 690-8.

1090

(114) Lee, C. H.; Cook, J. L.; Mendelson, A.; Moioli, E. K.; Yao, H.; 1091 Mao, J. J. Regeneration of the articular surface of the rabbit synovial 1092 joint by cell homing: a proof of concept study. Lancet 2010, 3761093 (9739), 440-8.

(115) Toh, W. S.; Lee, E. H.; Guo, X. M.; Chan, J. K.; Yeow, C. H.; 1095 Choo, A. B.; Cao, T. Cartilage repair using hyaluronan hydrogel- 1096 encapsulated human embryonic stem cell-derived chondrogenic cells. 1097 Biomaterials 2010, 31 (27), 6968-80.

1098

(116) Kim, M.; Kim, S. E.; Kang, S. S.; Kim, Y. H.; Tae, G. The use of 1099 de-differentiated chondrocytes delivered by a heparin-based hydrogel 1100 to regenerate cartilage in partial-thickness defects. Biomaterials 2011, 1101 32 (31), 7883-96.

1102

(117) Kim, M.; Hong, B.; Lee, J.; Kim, S. E.; Kang, S. S.; Kim, Y. H.; 1103 Tae, G. Composite system of PLCL scaffold and heparin-based 1104 hydrogel for regeneration of partial-thickness cartilage defects. 1105 Biomacromolecules 2012, 13 (8), 2287-98.

1106

(118) Lee, H. R.; Park, K. M.; Joung, Y. K.; Park, K. D.; Do, S. H. 1107 Platelet-rich plasma loaded hydrogel scaffold enhances chondrogenic 1108 differentiation and maturation with up-regulation of CB1 and CB2. J. 1109 Controlled Release 2012, 159 (3), 332-7.

1110

(119) Ohshika, S.; Ishibashi, Y.; Kon, A.; Kusumi, T.; Kijima, H.; 1111 Toh, S. Potential of exogenous cartilage proteoglycan as a new material 1112 for cartilage regeneration. Int. Orthop 2012, 36 (4), 869-77. 1113

(120) Li, B.; Yang, J.; Ma, L.; Li, F.; Tu, Z.; Gao, C. Fabrication of 1114 poly(lactide-co-glycolide) scaffold filled with fibrin gel, mesenchymal 1115 stem cells, and poly(ethylene oxide)-b-poly(L-lysine)/TGF-beta1 1116 plasmid DNA complexes for cartilage restoration in vivo. J. Biomed. 1117 Mater. Res., Part A 2013, 101 (11), 3097-3108.

1118

(121) Solchaga, L. A.; Temenoff, J. S.; Gao, J.; Mikos, A. G.; Caplan, 1119 A. I.; Goldberg, V. M. Repair of osteochondral defects with 1120 hyaluronan- and polyester-based scaffolds. Osteoarthritis Cartilage 1121 2005, 13 (4), 297-309.

1122

(122) Frenkel, S. R.; Bradica, G.; Brekke, J. H.; Goldman, S. M.; 1123 Ieska, K.; Issack, P.; Bong, M. R.; Tian, H.; Gokhale, J.; Coutts, R. D.; 1124 Kronengold, R. T. Regeneration of articular cartilage-evaluation of 1125 osteochondral defect repair in the rabbit using multiphasic implants. 1126 Osteoarthritis Cartilage 2005, 13 (9), 798-807. 
1128 (123) Vinatier, C.; Gauthier, O.; Fatimi, A.; Merceron, C.; Masson, 1129 M.; Moreau, A.; Moreau, F.; Fellah, B.; Weiss, P.; Guicheux, J. An 1130 injectable cellulose-based hydrogel for the transfer of autologous nasal 1131 chondrocytes in articular cartilage defects. Biotechnol. Bioeng. 2009, 102 1132 (4), 1259-67.

1133 (124) Lam, J.; Lu, S.; Lee, E. J.; Trachtenberg, J. E.; Meretoja, V. V.; 1134 Dahlin, R. L.; van den Beucken, J. J.; Tabata, Y.; Wong, M. E.; Jansen, 1135 J. A.; Mikos, A. G.; Kasper, F. K. Osteochondral defect repair using 1136 bilayered hydrogels encapsulating both chondrogenically and 1137 osteogenically pre-differentiated mesenchymal stem cells in a rabbit 1138 model. Osteoarthritis Cartilage 2014, 22 (9), 1291-300.

1139 (125) Wang, W.; Sun, L.; Zhang, P.; Song, J.; Liu, W. An anti1140 inflammatory cell-free collagen/resveratrol scaffold for repairing 1141 osteochondral defects in rabbits. Acta Biomater. 2014, 10 (12), 1142 4983-95.

1143 (126) Lu, S.; Lam, J.; Trachtenberg, J. E.; Lee, E. J.; Seyednejad, H.; 1144 van den Beucken, J. J.; Tabata, Y.; Wong, M. E.; Jansen, J. A.; Mikos, A. 1145 G.; Kasper, F. K. Dual growth factor delivery from bilayered, 1146 biodegradable hydrogel composites for spatially-guided osteochondral 1147 tissue repair. Biomaterials 2014, 35 (31), 8829-39.

1148 (127) Needham, C. J.; Shah, S. R.; Dahlin, R. L.; Kinard, L. A.; Lam, 1149 J.; Watson, B. M.; Lu, S.; Kasper, F. K.; Mikos, A. G. Osteochondral 1150 tissue regeneration through polymeric delivery of DNA encoding for 1151 the SOX trio and RUNX2. Acta Biomater. 2014, 10 (10), 4103-12. 1152 (128) Han, F.; Yang, X.; Zhao, J.; Zhao, Y.; Yuan, X. Photo1153 crosslinked layered gelatin-chitosan hydrogel with graded composi1154 tions for osteochondral defect repair. J. Mater. Sci.: Mater. Med. 2015, 115526 (4), 160.

1156 (129) Mazaki, T.; Shiozaki, Y.; Yamane, K.; Yoshida, A.; Nakamura, 1157 M.; Yoshida, Y.; Zhou, D.; Kitajima, T.; Tanaka, M.; Ito, Y.; Ozaki, T.; 1158 Matsukawa, A. A novel, visible light-induced, rapidly cross-linkable 1159 gelatin scaffold for osteochondral tissue engineering. Sci. Rep. 2014, 4, 11604457.

1161 (130) Leone, G.; Fini, M.; Torricelli, P.; Giardino, R.; Barbucci, R. An 1162 amidated carboxymethylcellulose hydrogel for cartilage regeneration. J. 1163 Mater. Sci.: Mater. Med. 2008, 19 (8), 2873-80.

1164 (131) Bal, B. S.; Rahaman, M. N.; Jayabalan, P.; Kuroki, K.; Cockrell, 1165 M. K.; Yao, J. Q.; Cook, J. L. In vivo outcomes of tissue-engineered 1166 osteochondral grafts. J. Biomed. Mater. Res., Part B 2010, 93 (1), 1641167174.

1168 (132) Zhang, W.; Lian, Q.; Li, D.; Wang, K.; Hao, D.; Bian, W.; He, 1169 J.; Jin, Z. Cartilage repair and subchondral bone migration using 3D 1170 printing osteochondral composites: a one-year-period study in rabbit 1171 trochlea. BioMed Res. Int. 2014, 2014, 746138.

1172 (133) Ge, Z.; Li, C.; Heng, B. C.; Cao, G.; Yang, Z. Functional 1173 biomaterials for cartilage regeneration. J. Biomed. Mater. Res., Part A 1174 2012, 100 (9), 2526-2536.

1175 (134) Toh, W. S.; Spector, M.; Lee, E. H.; Cao, T. Biomaterial1176 mediated delivery of microenvironmental cues for repair and 1177 regeneration of articular cartilage. Mol. Pharmaceutics 2011, 8 (4), 1178 994-1001.

1179 (135) Chu, C. R.; Szczodry, M.; Bruno, S. Animal models for 1180 cartilage regeneration and repair. Tissue Eng., Part B 2010, 16 (1), 1181 105-115.

1182 (136) Rasanen, T.; Messner, K. Regional variations of indentation 1183 stiffness and thickness of normal rabbit knee articular cartilage. $J$. 1184 Biomed. Mater. Res. 1996, 31 (4), 519-524.

1185 (137) Ahern, B. J.; Parvizi, J.; Boston, R.; Schaer, T. P. Preclinical 1186 animal models in single site cartilage defect testing: a systematic 1187 review. Osteoarthritis Cartilage 2009, 17 (6), 705-13.

1188 (138) Aigner, T.; Cook, J. L.; Gerwin, N.; Glasson, S. S.; Laverty, S.; 1189 Little, C. B.; Mcllwraith, W.; Kraus, V. B. Histopathology atlas of 1190 animal model systems - overview of guiding principles. Osteoarthritis 1191 Cartilage 2010, 18 (Suppl 3), S2-S6.

1192 (139) Shapiro, F.; Koide, S.; Glimcher, M. J. Cell origin and 1193 differentiation in the repair of full-thickness defects of articular 1194 cartilage. J. Bone Joint Surg Am. 1993, 75 (4), 532-553.
(140) Koch, T. G.; Betts, D. H. Stem cell therapy for joint problems 1195 using the horse as a clinically relevant animal model. Expert Opin. Biol. 1196 Ther. 2007, 7 (11), 1621-6.

1197

(141) Convery, F. R.; Akeson, W. H.; Keown, G. H. The repair of 1198 large osteochondral defects. An experimental study in horses. Clin. 1199 Orthop. Relat. Res. 1972, 82, 253-262.

1200

(142) Shortkroff, S.; Barone, L.; Hsu, H. P.; Wrenn, C.; Gagne, T.; 1201 Chi, T.; Breinan, H.; Minas, T.; Sledge, C. B.; Tubo, R.; Spector, M. 1202 Healing of chondral and osteochondral defects in a canine model: the 1203 role of cultured chondrocytes in regeneration of articular cartilage. 1204 Biomaterials 1996, 17 (2), 147-154.

1205

(143) Lu, Y.; Markel, M. D.; Swain, C.; Kaplan, L. D. Development 1206 of partial thickness articular cartilage injury in an ovine model. J. 1207 Orthop. Res. 2006, 24 (10), 1974-82.

1208

(144) Frisbie, D. D.; Cross, M. W.; Mcllwraith, C. W. A comparative 1209 study of articular cartilage thickness in the stifle of animal species used 1210 in human pre-clinical studies compared to articular cartilage thickness 1211 in the human knee. Vet. Comp. Orthop. Traumatol. 2006, 19 (3), 142- 1212 146.

1213

(145) Hepp, P.; Osterhoff, G.; Niederhagen, M.; Marquass, B.; 1214 Aigner, T.; Bader, A.; Josten, C.; Schulz, R. Perilesional changes of 1215 focal osteochondral defects in an ovine model and their relevance to 1216 human osteochondral injuries. J. Bone Jt. Surg., Br. Vol. 2009, 91 (8), 1217 $1110-1119$.

1218

(146) Kim, H. K.; Moran, M. E.; Salter, R. B. The potential for 1219 regeneration of articular cartilage in defects created by chondral 1220 shaving and subchondral abrasion. An experimental investigation in 1221 rabbits. J. Bone Joint Surg Am. 1991, 73 (9), 1301-1315. 1222

(147) Bonasia, D. E.; Marmotti, A.; Massa, A. D.; Ferro, A.; Blonna, 1223 D.; Castoldi, F.; Rossi, R. Intra- and inter-observer reliability of ten 1224 major histological scoring systems used for the evaluation of in vivo 1225 cartilage repair. Knee Surg. Sports Traumatol. Arthrosc. 2014, 1226 DOI: $10.1007 / \mathrm{s} 00167-014-2975-8$.

1227

(148) Rutgers, M.; van Pelt, M. J.; Dhert, W. J.; Creemers, L. B.; 1228 Saris, D. B. Evaluation of histological scoring systems for tissue- 1229 engineered, repaired and osteoarthritic cartilage. Osteoarthritis 1230 Cartilage 2010, 18 (1), 12-23.

1231

(149) Orth, P.; Zurakowski, D.; Wincheringer, D.; Madry, H. 1232 Reliability, Reproducibility, and Validation of Five Major Histological 1233 Scoring Systems for Experimental Articular Cartilage Repair in the 1234 Rabbit Model. Tissue Eng., Part C 2012, 18 (5), 329-339. 1235

(150) Hurtig, M. B.; Buschmann, M. D.; Fortier, L. A.; Caroline D. 1236 Hoemann Ernest B. Hunziker; Jurvelin, J. S.; Mainil-Varlet, P.; 1237 Mcllwraith, C. W.; Sah, R. L.; Whiteside, R. A., Preclinical Studies for 1238 Cartilage Repair: Recommendations from International Cartilage 1239 Repair Society. Cartilage 2011, 2 (2), 137-152, DOI.10.1177/ 1240 1947603511401905

1241

(151) Standard Guide for in Vivo Assessement of Implantable Devices 1242 Intended to Repair or Regenerate Articular Cartilage; ASTM F2451-05 ; 1243 ASTM International: West Conshohocken, NJ, 2010. 